San Jose State University

SJSU ScholarWorks

Master's Theses

Master's Theses and Graduate Research

1993

\title{
A Descriptive study of the categories of psychotropic medications prescribed for the inpatients in three of the California State Mental Health Hospitals
}

Susan Henderson

San Jose State University

Follow this and additional works at: https://scholarworks.sjsu.edu/etd_theses

\section{Recommended Citation}

Henderson, Susan, "A Descriptive study of the categories of psychotropic medications prescribed for the inpatients in three of the California State Mental Health Hospitals" (1993). Master's Theses. 541. DOI: https://doi.org/10.31979/etd.7mnd-7mma https://scholarworks.sjsu.edu/etd_theses/541

This Thesis is brought to you for free and open access by the Master's Theses and Graduate Research at SJSU ScholarWorks. It has been accepted for inclusion in Master's Theses by an authorized administrator of SJSU ScholarWorks. For more information, please contact scholarworks@sjsu.edu. 


\section{INFORMATION TO USERS}

This manuscript has been reproduced from the microfilm master. UMI films the text directly from the original or copy submitted. Thus, some thesis and dissertation copies are in typewriter face, while others may be from any type of computer printer.

The quality of this reproduction is dependent upon the quality of the copy submitted. Broken or indistinct print, colored or poor quality illustrations and photographs, print bleedthrough, substandard margins, and improper alignment can adversely affect reproduction.

In the unlikely event that the author did not send UMI a complete manuscript and there are missing pages, these will be noted. Also, if unauthorized copyright material had to be removed, a note will indicate the deletion.

Oversize materials (e.g., maps, drawings, charts) are reproduced by sectioning the original, beginning at the upper left-hand corner and continuing from left to right in equal sections with small overlaps. Each original is also photographed in one exposure and is included in reduced form at the back of the book.

Photographs included in the original manuscript have been reproduced xerographically in this copy. Higher quality $6 " \mathrm{~m}$ " 9 " black and white photographic prints are available for any photographs or illustrations appearing in this copy for an additional charge. Contact UMI directly to order.

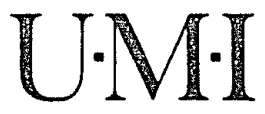



Order Number 1353018

A descriptive study of the categories of psychotropic medications prescribed for the inpatients in three of the California State Mental Health Hospitals

\author{
Henderson, Susan, M.S. \\ San Jose State University, 1993
}

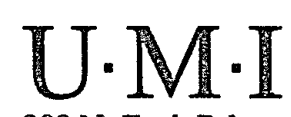

300 N. Zeeb Rd.

Ann Arbor, MI 48106 



\begin{abstract}
A DESCRIPTIVE STUDY OF THE CATEGORIES OF PSYCHOTROPIC MEDICATIONS PRESCRIBED FOR THE INPATIENTS IN THREE OF THE CALIFORNIA STATE MENTAL HEALTH HOSPITALS
\end{abstract}

\author{
A Thesis \\ Presented to \\ The Faculty of the Department of Nursing \\ San Jose State University
}

\author{
In Partial Fulfillment \\ of the Requirements for the Degree \\ Master of Science
}

by

Susan Henderson

May, 1993 
APPROVED FOR THE DEPARTMENT OF NURSING

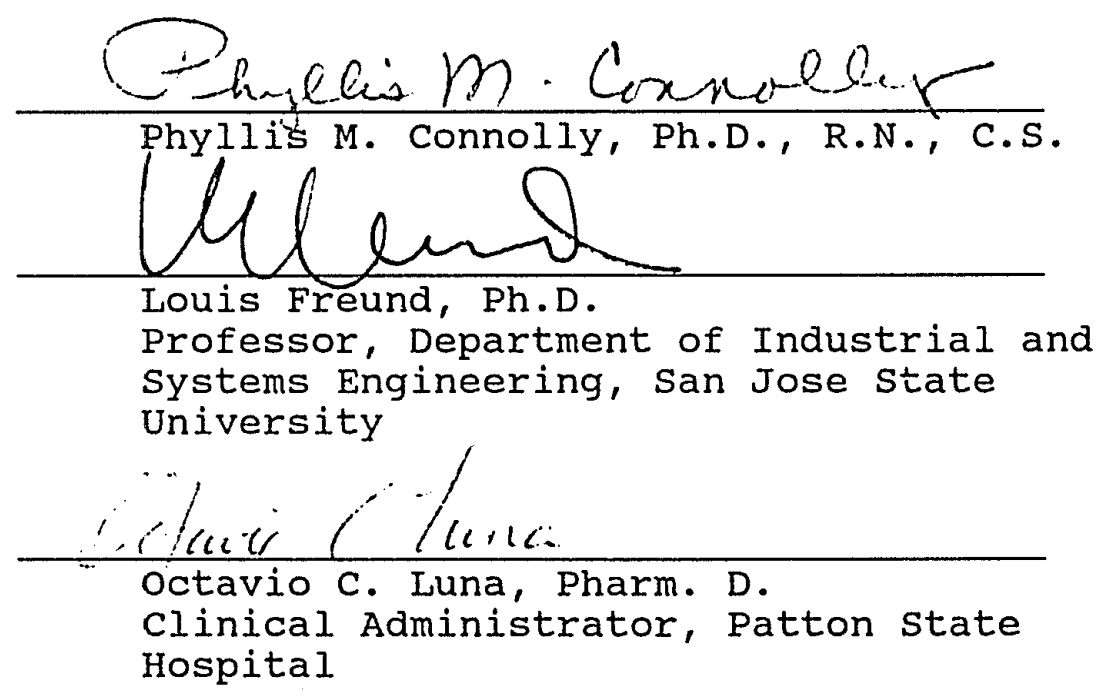

APPROVED FOR THE UNIVERSITY

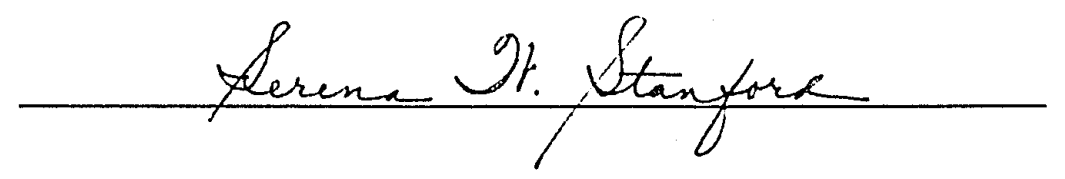




\section{ABSTRACT}

A DESCRIPTIVE STUDY OF THE CATEGORIES OF PSYCHOTROPIC MEDICATIONS PRESCRIBED FOR THE INPATIENTS IN THREE OF THE CALIFORNIA STATE MENTAL HEALTH HOSPITALS

By Susan Henderson

This thesis describes the categories of psychotropic medications being prescribed for the inpatients in three of the California state Mental Health Hospitals. It utilizes a descriptive research design. The data were collected during the same time frame as the California staffing standards Study of June 1992 .

There are nursing activities that are necessary for effective use of the psychotropic medications, including assessment and monitoring of patients for effectiveness and side effects, administration, interventions for side effects and patient teaching. These activities translate into a certain amount of workload.

The data reflected the categories of psychotropic medication being prescribed that would be expected in the patient population and validated that there would be expected workload demands based on the results. Eighty-one percent of the patients were prescribed psychotropic medications. The data suggest correlation with workload and did generate further research questions for the future. 


\section{ACKNOWLEDGEMENTS}

To my Father, Chester S. Wrzos, and mother, Martha (June) Hodges Wrzos, both of whom inherently taught me the value of knowledge.

AND

To my children, Jere and Wendi,

who have tolerated my need for a higher education

and given me absolute love and support.

AND

To Phyllis, my first reader and mentor, who guided me through the dark times. 
IIST OF TABLES . . . . . . . . . . . . . . . . . . vii Chapter

1. INTRODUCTION . . . . . . . . . . . . 1

The Problem and Research Questions . . . . 2 Purpose and Need . . . . . . . . . . . 3 Definition of Terms. . . . . . . . . . 4 Research Design. . . . . . . . . . . 5 Scope and Iimitations. . . . . . . . . 5

2. CONCEPTUAL FRAMEWORK AND REVIEW OF RELATED IITERATURE . . . . . . . . . . . . . 7 Conceptual Framework. . . . . . . . . . 7 Review of Related Literature . . . . . . 10 Summary. . . . . . . . . . . . . 25

3. METHODOLOGY. . . . . . . . . . . . . . 27 Study Design . . . . . . . . . . . . . 27 subjects . . . . . . . . . . . . . . 27 Human Subjects Approval. . . . . . . . . 28 Data Collection. . . . . . . . . . . 29 Data Analysis. . . . . . . . . . . . 29

4. ANALYSIS AND INTERPRETATION OF THE DATA. • • 31 Summary. . . . . . . . . . . . . 62

5. CONCLUSIONS AND RECOMMENDATIONS. . . . . . 64 


\section{Chapter}

REFERENCES . . . . . . . . . . . . . . . 75

BIBLIOGRAPHY • • • • • • • • • • • • • • • 79 APPENDIXES

A. Neuroleptic Medications. . . . . . 83

B. Antidepressant Medications . . . . 85

C. Anxiolytic Medications . . . . . . 87

D. Human Subjects-Institutional Review

Board Letter of Approval . . . . . 89

E. Psychotropic Medications Used in the

study Units. . . . . . . . . . . . 91 
IIST OF TABLES

Table

Page

1. Percent of all patients on neuroleptic medications . . . . . . . . . . .

2. Percent of patients on neuroleptic medications in all hospitals/units. . . .

3. Percent of patients on neuroleptic medications compared by hospital. . . .

4. Percent of patients on neuroleptic medications compared by unit type . . .

5. Range of acuity compared with average

use of neuroleptic medications in all

hospitals. . . . . . . . . . 36

6. Percent of all patients on antidepressant medications . . . . . . . . . . .

7. Percent of patients on antidepressant medications in all hospitals/units. . . 38

8. Percent of patients on antidepressant medications compared by hospital . . . . 39

9. Percent of patients on antidepressant medications compared by unit type . . . . 40 
10. Range of acuity compared with average use of antidepressant medications in all hospitals. . . . . . . . . . . . 41

11. Percent of all patients on anxiolytic medications . . . . . . . . . . .

12. Percent of patients on anxiolytic medications in all hospitals/units . . . 43

13. Percent of patients on anxiolytic medications compared by hospital . . . . 44

14. Percent of patients on anxiolytic medications compared by unit type. . . . 45

15. Range of acuity compared with average use of anxiolytic medications in all hospitals. . . . . . . . . . 46

16. Percent of all patients on sedative/hypnotic medications. . . . . 47

17. Percent of patients on sedative/hypnotic medications in two hospitals/units. . . . 48

18. Percent of patients on sedative/hypnotic medications compared by unit type . . . . 49

19. Percent of all patients on lithium. . . . . 50 20. Percent of patients on lithium in all hospitals/units. . . . . . . . . . 51 
21. Percent of patients on Iithium compared by hospital . . . . . . . . . . . 52

22. Percent of patients on Iithium compared by unit type . . . . . . . . . . . 53

23. Range of acuity compared with average use of lithium in all hospitals. . . . . 54

24. Percent of all patients on other antimanic medications. . . . . . . . . . 56

25. Percent of patients on other antimanic medications in all hospitals/units . . . 57

26. Percent of patients on other antimanic medications compared by hospital . . . . 58

27. Percent of patients on other antimanic medications compared by unit type . . . 59

28. Range of acuity compared with average use of other antimanic medications in all hospitals . . . . . . . . . . . 61 
Chapter 1

INTRODUCTION

Psychotropic medications, first introduced in the 1950's for the treatment of psychiatric conditions, dramatically shifted the methods of care for the mentally ill population. Before 1955 the populations in mental hospitals had been steadily increasing; with the introduction of psychotropic medications there was a sharp decrease that occurred and continues to decline. These drugs have enabled many of the mentally ill to be treated solely as outpatients. Others return to institutions for acute exacerbations of their disease, while a percentage remain institutionalized.

If mentally ill patients' symptoms are decreased by using psychotropic medications, as indicated by the decline in the populations in the mental hospitals, does this imply that these patients need less care while institutionalized than in the past? Is there a relationship between the type of psychotropic medications being utilized in an inpatient psychiatric hospital and staffing workload? Does it take more or less staff to care for patients on specific types of medications and why? Research has yet to be conducted that can answer these questions.

Periodic staffing studies of state mental health hospitals have been conducted to evaluate the number and 
type of staff needed to provide care to the inpatients (California, 1979; Freund, L., Connolly, P., Diasio-Serret, K., \& Parker, H., 1992; New York, 1983; Nutter, R. E. \& Marlow, H. A., 1985; Willcutt, H. C. \& Hart, R. V., 1989). These studies took into consideration the changing social policies, difficult economic times, an increase in regulations, and our aging society. The studies assess workload activities; however, to this date, no specific data on the types of medications being prescribed at the time of staffing studies have been published.

of the seriously mentally ill patients who are being cared for in psychiatric institutions, the modalities of treatments, as well as the specific medications prescribed, will vary. Since psychotropic medications continue to have effects which require continuous monitoring, evaluation, and patient teaching, it was determined that a descriptive study of the categories currently being prescribed by the California Department of Mental Hea?th, Division of State Hospitals (State Hospitals) would be useful.

The Problem and Research Questions The objective of this study was to describe and analyze the types of psychotropic medications being prescribed at the unit level in three state hospitals. This information would be included as a component of the demographics in the California staffing standards study of June 1992 . 
The following research questions were posed:

1. What are the categories of psychotropic medications being prescribed in three of the California State Hospitals, Department of Mental Health?

2. What is the usage of the categories in the total population, in each hospital, in all units across the hospitals, and among unit types?

3. Is the percent of patients in each category similar in each of the hospitals, in all units across the hospitals, and among unit types?

4. What is the usage of the categories in the various acuity levels within the three hospitals and the different unit types?

Purpose and Need

Considering the profound effect that psychotropic medications have had on the treatment of the mentally ill, it would appear reasonable to begin to assess the medication urage across units and institutions. If the categories of medications being prescribed in a unit change, it may reflect the type of patient being treated and therefore the staffing of that unit.

Once this type of data is collected routinely during staffing studies, other trends and practices could be 
studied, such as the relationship between workload and type of drug prescribed.

\section{Definition of Terms}

For the purpose of this study, the following operational definitions were used:

1. Study Units are the units designated in each facility that participated in the June 1992 staffing standards study and submitted pharmacy data.

2. Psychopharmacology is "the science of drugs having an effect on psychomotor behavior and emotional states" (Taber's, 1965, p. 120).

3. Psychotropic medications are medications used in the treatment of mental disorders. They interact with the cells in the brain, which causes behavioral changes. They are classified into antipsychotic (neuroleptic), antidepressant, anxiolytic, and antimanic.

4. Antipsychotic (neuroleptic) medications are used to treat "psychotic symptoms, regardless of cause or origin" (Harris, 1988, p. 1508).

5. Antidepressant medications are used for the alleviation of depression; they include the two common classes, heterocyclic antidepressants and 
monoamine oxidase (MAO) inhibitors (Murrey, 1991, p. 5).

6. Anxiolytic medications are used for the primary purpose of reducing or controlling anxiety and agitation (Murrey, 1991, p. 5).

7. Antimanic medications are "useful for the management of acute manic psychosis and certain schizoaffective conditions and as a prophylactic agent in selected bipolar, unipolar depressions and mania. These medications include lithium, Carbamazepine, Clonazepam, and Valproic Acid" (Murrey, 1991, p. 5).

\section{Research Design}

The research design used is a non-experimental, descriptive study. Data were collected from the pharmacy at each of three state hospitals. Each pharmacy concurrently collects this data for their own information. Data elements include the category of psychotropic drug by study unit. The data were collected during the same time frame as the staffing study.

Scope and Limitations

The California Department of Mental Health, Division of State Hospitals contracted with the Department of Industrial and Systems Engineering at San Jose State University to conduct a staffing study. The staffing study "was focused 
on establishing staffing guidelines ... at five hospitals serving the mentally ill" (Freund et al., 1992, p. 4). The descriptive study of psychotropic medications was a part of that staffing standards study and cannot be generalized to state hospitals in other states.

Only three of the state hospitals involved in the staffing study were able to participate in this study due to the inability to produce the necessary data without being too labor intensive; therefore, generalizations to the other hospitals in the system are limited. In each of the three hospitals, only the defined study units that were involved in the staffing study were included and submitted pharmacy data, thus limiting the generalizations to those units. Another limitation of the study was that the state hospitals provided different data sets. Two hospitals provided data on individual medications per patient; the third hospital had already categorized their medications. In one of the hospitals, there was an inability to get accurate census levels for each study unit, again limiting the ability to make broad hospital wide assumptions based on the findings of this study.

The study was also limited due to the inability to determine when psychotropic medications were being prescribed for the primary purpose of treating medical conditions. 
Chapter 2

CONCEPTUAL FRAMEWORR AND RELATED IITERATURE

The conceptual framework for this study includes the biological theories for mental illness and Dorothy Orem's self care theory.

\section{Biological Theories}

The success of psychotropic medications is based on the theory that behavior, thoughts and emotions are the result of the activity of nerve cells (Lickey \& Gordon, 1983, p. 13). This biological theory of mental illness began to be seriously studied with "two simultaneous discoveries." The first was the empirical discovery of medications which "...could alter perception, mood, thinking and behavior." The second was the "chemical theory of neurotransmission" that replaced the electrical theory of how the brain worked (Sullivan \& Sullivan, 1984, p. ix).

Biological theories support the concept that mental illness can be attributed to abnormalities in the central nervous system. The abnormalities are thought to be due to the way the neurons chemically transmit messages. Psychotropic medications work by changing the transmission process. "In other words, biological therapies often yield healing because they produce changes in the function of cells in the central nervous system, which permits the 
emergence of new behavior" (Wilson, \& Kneisl, 1988, p. 852). The ultimate goal of drug therapies is to make the individual a productive member of society and improve their quality of life. For many mentally ill individuals, drug therapies allow them to improve to the point that they may benefit by the other therapy modalities, eventually care for themselves, and be able to live in the least restrictive setting .

Nursing Conceptual Framework

Self care has been defined by Dorothy Orem (1980) as "...the practice of activities that individuals initiate and perform on their own behalf in maintaining life, health, and well being" (p. 35). In her self care theory there are defined requirements that she identifies as universal, developmental, and health deviation (Orem, 1980, p. 41). Universal requirements include common needs of all people, such as the need for air, water, or food (Orem, 1980, p. 42). Developmental requirements include developmental life stages, such as childhood, adulthood, and requirements brought about by changes that occur, such as the death of a spouse (Orem, 1980, p. 47). Health-deviation requirements "exist for persons who are ill, are injured, have specific forms of pathology.... and who are under medical diagnosis and treatment" (Orem, 1980, p. 48). 
Mental illness may impact any or all of Orem's cited requirements. "When a change in health state brings about total or almost total dependence on others for the needs to sustain life or well-being, the person moves from the position of self-care agent to that of patient or receiver of care" (Orem, 1980, p. 49).

Orem defines "nursing" as providing necessary care for an individual "... on a continuous basis in order to sustain Iife and health, recover from disease or injury, and cope with their effects" (Orem, 1980, p. 6). She recognized three different roles nursing may play for individuals: (a) the role of complete care giver--performing all of the necessary requirements; (b) partial care giver--assisting in some aspects of their care requirements; and (c) primarily providing support and/or education to the individual who is providing their own care (Orem, 1980, pp. 97 - 98).

Nursing actions performed to deliver care or enable the patient to render their own self care translates into workload activities. This means that the activity occurs as a result of the nurse or care giver providing a certain amount of work and time to perform the activity. In summary, biological theories support the ability of psychotropic medications to control symptoms of mental illness. Once symptoms are controlled, individuals can then benefit from other treatment modalities, enabling many to 
care for themselves and remain in or return to the community. Patients who must remain in hospitals for care still benefit from the use of these medications by increasing their level of functioning.

Self care can be viewed on a continuum: at one end are individuals who can provide total care for themselves, with no need of nursing care; at the other end of the continuum are individuals who cannot provide self care and must rely on nursing to care for their needs. It would appear that the need for nursing care and thus nursing time is increased as individuals move closer to the end of the continuum where they cannot provide their own care.

\section{Related Iiterature}

Review of the literature revealed prolific information available on psychotropic medications and a small amount on workload and staffing issues in mental health hospitals, but no information on correlations between type of psychotropic medication being used and nursing workload.

For the purpose of this thesis, the literature will be reviewed under the following subject areas: (a) psychopharmacology, (b) psychotropic medications, (c) psychotropic medications and workload issues, and (d) current staffing methodologies for mental health hospitals. 
Psychopharmacology

Caldwell (1970) defined psychopharmacology as "...utilization of drugs in restoring or maintaining mental health, and for exploring the mind...." (p. 3). The use of medications or chemical agents to treat patients with mental disorders "developed with the history of man" (Mason \& Granacher, 1980, p. 3). Caldwell (1970) describes the use of mind altering drugs from "time immemorial" (p. 21) with the use of "mushrooms and other psychedelic drugs" (p. 21). Many consider 1845 the year that true psychopharmacology began. In this year, Moreau de Tours used a drug to induce and study mental symptoms and also to treat mental disease. The drug was cannabis (marijuana) and Moreau is considered the first true psychopharmacologist. Other medications developed and utilized during the nineteenth and early twentieth century included chloral hydrate, cocaine, sodium bromide and methylene blue. However, most references unanimously agree that modern psychopharmacology had its beginning in 1952 with the use of chlorpromazine (Thorazine).

Chlorpromazine was first synthesized in 1950 by Paul Christopentier and was used by a surgeon to "alleviate preoperative anxiety, to reduce surgical stress and to prevent postoperative consequences" (Caldwell, 1970, p. 4). Henri Laborit, the surgeon, recognized the drug's potential 
and recommended its use in psychiatry. Its first use proved to be exceptionally successful. The psychotic patient on whom it was first used was well three weeks after drug therapy was initiated (Caldwell, 1970, p. 4). This revolution in drug therapy marked the beginning of a new era for the treatment of mental illness.

"The new drugs were revolutionary because they worked. Previously, effective treatments for severe mental iliness had been virtually unknown" (Lickey \& Gordon, 1983, p. 3). "Thorazine transformed the atmosphere in the disturbed wards. Physical restraints were a thing of the past--and the milieu became therapeuticl" Thorazine "improved psychiatric therapy most dramatically where ic was most needed, in large mental hospitals." Its use enabled patients to be treated as outpatients (Caldwell, 1970, p. 12).

The effect of these new medications coupled with the government's push to deinstitutionalize the mentally ill has resulted in a decrease in the population of mental health hospitals. In the United states, during the first half of the twentieth century, the number of patients in mental health facilities continuously increased from 150,000 to 500,000. After the new medications were in use in 1965, there was a decline of patients in institutions. In 1975, 
the number of patients hospitalized was around 200,000. The decline has continued (Lickey \& Gordon, 1983, p. 4).

The Psychotropic Medications

Psychotropic medications are all medications used in the treatment of mental disorders. They are classified into antipsychotic (neuroleptic), antidepressant, anxiolytic, and antimanic.

Antipsychotic or neuroleptic medications are used to treat psychoses. They are commonly classified by chemical structure. There are six major classes, with one class, phenothiazine, also divided into three subclasses (Harris, 1981, p. 1316). Appendix A lists the neuroleptic medications by both the generic and trade names. "The term neuroleptic means 'reduced neurologic tension" (Mason \& Granacher, 1980, p. 6). Neuroleptics "... all produce the 'neuroleptic syndrome' in man. This consists of a reduction in psychotic symptoms of hallucinations, mental confusion, and delusions; reduction of psychomotor agitation, such as aggressive, assaultive or destructive behavior; inhibition of panic, fear and hostility; reduction of spontaneous movements and purposeful actions; and increased indifference towards surroundings but without impairing the sensorium or producing ataxia" (Mason \& Granacher, 1980, p. 7). "Controlled studies have failed to demonstrate substantial differences in antipsychotic 
effects among the medications. The choice of a particular medications, then, depends on knowledge of the various pharmacologic properties and side effects, the client's or family member's history of drug response, and the psychiatrist's experience with the various compounds" (Wilson \& Rneisl, 1988, p. 855).

Neuroleptic nedications are administered by injection, intramuscular (IM) or intravascular (IV), and orally. If treatment is for an acute psychotic episode, injection is the preferred method, allowing for faster action of the drug and assuring administration of the medication. Initial doses should be slowly increased based on the pacients tolerance to side effects and their therapeutic response. Patients must be closely monitored to detect and treat side effects. Monitoring is accomplished by "clinical observation and judgement" (Harris, 1988, p. 1509). When patients' symptoms are controlled, the doses are reduced until stabilized at the lowest effective dose.

Side effects of the neuroleptics include sedation, hypotension, anticholinergic effects, and extrapyramidal effects. Each drug varies in the degree that side effects are exhibited. Sedation is an early side effect in therapy. It occurs when the medications are first being used and tolerance normally develops within the first or second week of therapy. 
Hypotension is a common side effect. It occurs more often in patients being administered parenteral medications than in those being administered oral preparations. Anticholinergic effects include blurred vision, dry mouth, constipation, urinary retention, decreased perspiration, and increased heart rate.

Extrapyramidal reactions are typically considered mediated via blockade of central dopaminergic receptors involved in motor functions (McEvoy, G., Litvak, K., Welsh, O., Dewey, D., Fong, P., Ford, M., Douglas, P., ShannonLass, E., Epstein, M., Kester, L., Campbell, J., Frederickson, M., and Ziegler, K., 1993, p. 1330). These reactions include pseudoparkinsonism, akathisia, dystonia, and tardive dyskinesia. Pseudoparkinsonism includes signs and symptoms of muscle rigidity, tremor, and masklike faces, shuffling gait, drooling and slow voluntary movement. Akathisia is characterized by constant motion, inability to sit, and pacing. Dystonias are involuntary muscular movements, usually of the eye, neck, and jaw. All three of these side effects are reversible with either the reduction in dosage, change of medications, or the addition of antiparkinsonian medications.

Antidepressant medications are used for the alleviation of depression; they include the two common classes, heterocyclic antidepressants and monoamine oxidase 
(MAO) inhibitors (Murrey, 1991, p. 5). The heterocyclic

class includes tricyclics, tetracyclics, and triazolopyridine. The listing of antidepressants can be found in Appendix B.

Symptoms of depression that necessitate use of antidepressants includes a depressed mood of two weeks duration or longer, in addition to other symptoms such as 10ss of energy and interest in normal activities, sleep and eating disturbances, inability to concentrate, feelings of guilt, and psychomotor retardation or agitation, or suicide ideation.

Antidepressants can be administered by injection or by mouth; however, the most common method is by mouth. Initially antidepressant medication is usually given in small doses and increased slowly based on the patient's therapeutic response and tolerance to side effects. Monitoring of plasma level is often helpful. Maximum therapeutic response may not occur for several weeks after medications are administered.

The heterocyclic antidepressants are the medications of choice to treat depression. Side effects include anticholinergic effects, cardiac effects, tremors, seizures, nightmares, weight gain, agitation, and extrapyramidal effects. 
Anticholinergic effects are blurred vision, dry mouth, constipation, urinary retention, increased perspiration, precipitation of glaucoma and anticholinergic delirium. Cardiac effects can include palpitations, mild tachycardia, cardiac conduction block, or arrhythmia. Tricyclics have been known to cause sudden death. Elderly patients and those with heart disease require an electrocardiogram before starting treatment and periodically thereafter.

Sedation tends to be one of the most common side effects and often requires a medication change in some patients.

Monoamine oxidase inhibitors (MAOI) are used in patients who do not respond to treatment with the heterocyclic or patients with atypical depression. Symptoms of atypical depression include anxiety, mood fluctuations, fatigue, overeating with weight gain, and hypersomnia. MAOI's are also useful for patients who experience phobias or panic attacks.

Patients taking MAOI's must be made aware not to eat foods that contain tyramine, such as cheese, wines, or chicken liver. Combining these medications with tyramine can increase its pressor effect, causing a hypertensive crisis.

Anxiolytic (antianxiety) medications are used for the primary purpose of reducing or controlling anxiety and 
agitation (Murrey, 1991, p. 5). They are also called minor tranquilizers and include certain medications from the following classes: antihistamines, barbiturates, propanediols, beta-adrenergic blockers, and benzodiazepines (Appendix C) .

Symptoms commonly exhibited in anxiety include tension, fear, dread, or terror. Other uses of anxiolytic medications include panic-attack disease, restlessness, insomnia, tension, senile agitation, muscle disorders, somatoform disorders, personality disorders, acute alcoholism and hysteria.

While some of the anxiolytic medications can be administered by injection or by mouth, most of the medications are only available in oral compounds. The oral route tends to be absorbed more quickly, consistently and completely than IM injections, but not IV injections. Effectiveness is evident within one to two days of therapy. All of the anxiolytic medications are capable of being used as a sedative-hypnotic in doses larger than those used for antianxiety. It is not recommended to use them for insomnia in mental illness. "Insomnia can and should be treated as part of the larger problem, and sedative antipsychotics or antidepressants may be given at bedtime to accomplish this purpose" (Wilson \& Kneisl, 1988, p. 883). 
Sedation is an expected side effect with the use of most of these medications; however, with the proper dosage, it should be minimal. Other common side effects are dizziness, dry mouth, headaches, gastrointestinal complaints, nervousness, and blurred vision. Rare effects may be rashes, fatigue, ataxia, diplopia, palpitations, and slurred speech.

Antimanic medications are "useful for the management of acute manic psychosis and certain schizoaffective conditions and as a prophylactic agent in selected bipolar, unipolar depressions and mania. These medications include lithium, carbamazepine, clonazepam, and valproic acid" (Murrey, 1991, p. 5). Lithium is the treatment of choice for these conditions; if it is not effective, the other medications are used.

Relative contraindications for the use of lithium include kidney and cardiovascular disease, severe debilitation, low-salt diet, diuretics, excess sweating, diarrhea, old age, and brain damage. Several baseline laboratory tests are necessary before starting lithium therapy.

Lithium is available only in oral forms--a solid oral dosage form or liquid. It is rapidly absorbed, reaching peak blood levels in one to three hours. Since there is a limited difference between therapeutic and toxic drug 
levels, blood testing is conducted daily when therapy is initiated. It is important to perform the blood draw at least 12 hours after the last dose to ensure correct results. Dosage is increased slowly until there is relief from symptoms or toxicity. This usually takes seven to fourteen days. Once symptoms are controlled, maintenance levels of lithium are based on blood levels that will control symptoms and present few side effects. At this point blood testing can be less often and finally only performed every one - two months.

Iithium toxicity can be fatal; therefore, careful monitoring of signs and symptoms is critical. Manifestations of lithium intoxication include drowsiness, confusion, giddiness, apathy, coarse hand tremor, and dysarthria. Gastrointestinal symptoms include nausea, vomiting and diarrhea. Other symptoms include blurred vision, vertical nystagmus, increased urination, ataxia, tinnitus, and muscle rigidity. It can result in coma, seizures, and cardiovascular collapse. The medication should be stopped upon the development of these signs to prevent severe toxicity. If toxicity is mild, medication may be withheld until lithium blood levels return into therapeutic range and the signs and symptoms have subsided. If it is severe, the drug is stopped and the patient is closely monitored by observation, blood pressure, and intake 
and output. Fluid and electrolytes may be needed (Harris, 1981, p. 1313).

Side effects of lithium can include cardiovascular problems, such as pulse irregularities and hypotension; central nervous system problems such as incontinence, slurred speech, blurred vision, dizziness; neuromuscular problems, such as ataxia, weakness, hyperactive deep tendon reflexes; gastrointestinal problems, such as nausea and vomiting, anorexia, and weight loss.

Carbamazepine is related to the tricyclic antidepressants and found to be effective within 10 days for the treatment of acute mania and prophylaxis of bipolar illness (Appleton, 1988, p. 136). The drug is administered orally and it is rapidly absorbed. Since it has a wider therapeutic/toxic range, blood levels do not have to be followed as closely as with lithium. Side effects are similar to the antidepressants.

Clonazepam, a benzodiazepine, and valproic acid, a anticonvulsant, have only been used for a short time. Little data is available on their effectiveness. Clonazepam is given orally, with side effects similar to other medications in its class. Valproic acid requires periodic liver function tests, since it has resulted in hepatotoxicity and death (Appleton, 1988, p. 137). 


\section{Psychotropic Medications and Workload Issues}

Nursing responsibilities and actions that are

necessary for effective use of the psychotropic medications include assessment and monitoring of patients for effectiveness and side effects, administration, interventions for side effects, and patient teaching.

Assessment and monitoring of patients for effectiveness and side effects include the activities of observation, clinical judgement, collecting appropriate data (i.e., vital signs), assuring appropriate tests are ordered and

performed, such as laboratory tests, electrocardiograms (EKGs), and alerting the physician to significant or abnormal results.

Physicians order medications for patients, but nursing personnel are with the patients 24 hours a day and have the responsibility to observe patients' behaviors and report them.

The ability to adequately assess and monitor patients for effectiveness and side effects includes possessing a thorough knowledge of the medications, their properties, and an ability to distinguish symptoms between a patient who is exhibiting side effects versus a patient whose psychotic symptoms are worsening. Since a certain portion of this assessment will be subjective, experience in psychiatric care will prove invaluable. 
Administration of the medications is oral or parental. Activities related to medication administration include assuring the medications have been ordered from the pharmacy, preparation of the medication, administration to the patient, and documentation.

Nursing interventions vary, based on the side effect being experienced by the patient. The intervention may be education, nursing actions, or reporting the side effect to the physician for an intervention.

An example of an education intervention may include teaching the patient experiencing hypotension not to change position from lying to standing rapidly. A second example would be educating the patient experiencing constipation on the best types of foods to eat, the importance of exercise, and liquid intake.

Examples of nursing action may include reassurance for side effects that are temporary, such as sedation and blurred vision. Additionally, the nurse must assure that a patient experiencing photosensitivity wears protective clothing, and sun block lotion if going out into the sun.

All significant or abnormal observations and abnormal test results should be reported to physicians. Even effects that may seem minor need physician awareness since these may be leading to toxicity in some medication. 
Teaching patients about their medications is a "major responsibility" for nurses (Wilson \& Rneisl, 1988, p. 853). Factors to be considered in effectively educating patients include individual learning abilities, cultural issues, socioeconomic class, health values, and the learning capability of the patient as it relates to where they are in their disorder (Wilson \& Rneisl, 1988, p. 854). Education does not occur at one time setting; it must be repetitive, and include feedback mechanisms to assure the patient is understanding what has been said. The method and amount of education will vary according to the patients readiness and ability to learn, which is related to the symptoms of the iliness.

Current staffing Methodologies

Current staffing methodologies for mental health hospitals are described in state staffing studies, articles, and nursing administration books on hospital mental health care. These references discuss staffing as it relates to the amount of time necessary for a nurse to accomplish a specific task or activity. For example, in the category of medications, the tasks measured in time include preparation, administration, and charting. There is no attempt to correlate this information with specific types of medications. 
The staffing studies are similar in their report design and methodology (California, 1979; Freund et al., 1992: New York, 1983; Nutter, R. E. \& Marlow, H. A., 1985; Willcut, 1989). Report design included an introduction providing information on the past history of staffing in that state, examples of other state studies, current legislation and regulatory expectations, budgetary issues, and identified assumptions on expectations of mental health care.

The methodology of the studies began with the identification of tasks by assessing patient's needs and staff activities. The next step was to determine the methods that would be used in defining the amount of time necessary to accomplish the specific task. These methods included time and motion studies, staff self-reporting, observations and workload sampling. Results were then analyzed statistically so that valid inferences could be made in staffing patterns.

\section{Summary}

The theoretical concepts used for this study include both the biological theories and Orems' self care theory. The biological theories indicate that the symptoms of mental illness can be controlled with the use of psychotropic medications. Once the treatment of symptoms provides relief to the patient, they may be able to participate in other treatments to enable them to provide their own self care. 
The progression in the self care continuum from needing total nursing care toward being able to care for themselves, should decrease the workload of the nursing staff.

The literature was reviewed under the following subject areas: (a) psychopharmacology, (b) psychotropic medications, (c) psychotropic medications and workload issues, and (d) current staffing methodologies for mental health hospitals. The literature revealed prolific information available on psychotropic medications and a small amount on workload and staffing issues in mental health hospitals. There was no information on correlations between type of psychotropic medication being used and nursing workload; therefore, this study used a descriptive approach to analyze the data. 


\section{Chapter 3}

\section{METHODOLOGY}

This chapter discusses the methodology used in describing the category of psychotropic medications by unit in three state hospitals. The methodology includes a) the study design, b) subjects, c) Human Subjects Approval, d) data collection, and e) analysis procedures.

\section{Study Design}

This was a non-experimental descriptive study designed to describe phenomena. It was used to further describe the patient populations involved in the 1992 staffing study. The data for the staffing study was calculated per category by the total number of patients who were on medications. For the purpose of this study, data were calculated per category by the total number of patients in the unit (census).

Five state hospitals participated in the staffing study; however, only three were able to participate in the study of psychotropic medications due to the inability to retrieve necessary data without being too labor intensive. subjects

The study population included approximately 768 patients in 20 different units. Two of the hospitals had six study units each and the third had eight study units. 
The study units were different types of patient units. Hospital A's study units totaled eight and included two Skilled Nursing units (SNF), three Child/Adolescent units, two Subacute units, and one Acute. Hospital $B$ and $C$ had a total of six units each. Hospital B's study units consisted of four Subacute Forensic and two Acute Forensic. Hospital C's study units were foux subacute Forensic, one Acute Forensic, and one Mentally Disordered offender unit (MDO). Human Subjects Approval

This study was designed to collect information on medications to describe the population and not use people as human subjects; therefore, a request for exemption from human subjects review was submitted to the Human SubjectsInstitutional Review Board at San Jose State University. After receipt of the exemption, the office of the review board requested further information clarifying the study. Finally, it was determined that a letter from the consultants for the staffing study releasing the data collected for use was needed. It was to stipulate that the data were to remain confidential, and not be used in such a way as to identify any single individual or facility. Once both of these documents were delivered, the request for exemption was approved (Appendix D). 
Data Collection

Data were collected during the same time frame as the staffing study. The first step in the data collection process was to determine the type of data that the hospitals could supply. This was accomplished through a site visit and telephone calls to all of the pharmacies. After the type of data available was determined, the participating hospitals were called to request the specific information desired. The information requested included a listing of all psychotropic medication per patient per study unit. Two of the three hospitals were able to supply this information. The third hospital was able to supply medication category per patient per unit.

Data collected as part of the staffing study on the acuity levels of the units were used for tinis paper. Acuity levels or the level of care of the patients is measured by the amount of time it takes to deliver the necessary care to a particular patient population. The acuity level was calculated by a mathematical equation and was designed to staff the units based on patient need not on unit type.

\section{Data Analysis}

The data were organized and categorized by unit and medication class. Descriptive and quantitative analysis were performed. The analysis searched for commonalities and 
variation among the data by unit and by hospital. Analysis also consisted of comparing and contrasting data collected on acuity levels in the staffing study and the medication data.

The data were collected to answer the research questions posed:

1. What are the categories of psychotropic medications being prescribed in three of the California state Hospitals, Department of Mental Health?

2. What is the usage of the categories in the total population, in each hospital, in all units across the hospitals, and among unit types?

3. Is the percent of patients on each category similar in each of the hospitals, in all units across the hospitals, and among unit types?

4. What is the usage of the categories in the various acuity levels within the three hospitals and the different unit types? 


\section{Chapter 4}

ANALYSIS AND INTERPRETATION OF THE DATA

A descriptive analysis of the data is presented in this chapter. The data are organized by each medication category, including neuroleptic, antidepressant, anxiolytic, and antimanic.

The unit usage percent of each category was calculated based on the total number of patients on that specific medication category by the total population of each unit. Each medication category is analyzed by use in the total patient population and total population per hospital; as well as by the unit usage percent in all hospitals, compared between all hospitals/units, compared between unit types, and compared with the acuity of the units. The presentation of the data and analysis will be divided by drug category. Neuroleptic Medications

Table 1 shows the neuroleptic medication use in the total patient population of each hospital and all combined. Hospital A has the lowest use percent. 
Table 1

Percent of all patients on neuroleptic medications

Total \# patients Total \# on neuroleptics (\%)

$\begin{array}{llll}\text { All Hospitals } & 768 & 623 & (81 \%) \\ \text { Hospital A } & 244 & 179 & (73 \%) \\ \text { Hospital B } & 266 & 219 & (82 \%) \\ \text { Hospital C } & 258 & 225 & (87 \%)\end{array}$

Table 2 presents neuroleptic usage percent ranges in all hospital units. The unit usage range is from $41 \%$ to $100 \%$ of the patient populations. Eleven or $55 \%$ of the twenty units had patient populations who used neuroleptics in the range of $81 \%-100 \%$.

Table 2

Percent of patients on neuroleptic medications in all hospitals/units

$n=20$ units

Range of

Percent

$41-60$

$61-80$

$81-100$

Total n

3

6

11

20
15

30

55

$\%$

100 
Table 3 displays neuroleptic unit usage compared between all hospitals. All hospitals usage percents were similar in the upper limits of neuroleptic usage, $50 \%$ or more of the units used from $81 \%-100 \%$. Hospital A was the only hospital with units using neuroleptics in the lowest range of $41-60 \%$.

Table 3

Percent of patients on neuroleptic medications compared by hospital.

$n=20$ units

Range of Hospital A Hospital B Hospital C

$\begin{array}{lllllll}\text { Percent } & \mathrm{n} & \% & \mathrm{n} & \% & \mathrm{n} & \%\end{array}$

\begin{tabular}{lcccccc}
\hline $41-60$ & 3 & 37.5 & 0 & & 0 & \\
$61-80$ & 1 & 12.5 & 3 & 50 & 2 & 33.3 \\
$81-100$ & 4 & 50 & 3 & 50 & 4 & 66.6 \\
Total & 8 & 100 & 6 & 100 & 6 & 99.9 \\
\hline
\end{tabular}

Table 4 shows neuroleptics usage in all unit types across the hospitals. The differences among the unit types is noted in the Child/Adolescent units. Each of the three Child/Adolescent units fell into a different usage range. 
In the Subacute Forensic units, $62.5 \%$ fell in the $61 \%-80 \%$ usage range. The two SNF units had a use range of $41 \%-60 \%$. The range of acuity is compared with the use of neuroleptics in Table 5. The two highest acuity ranges have a lower use of the neuroleptics than any other units. 


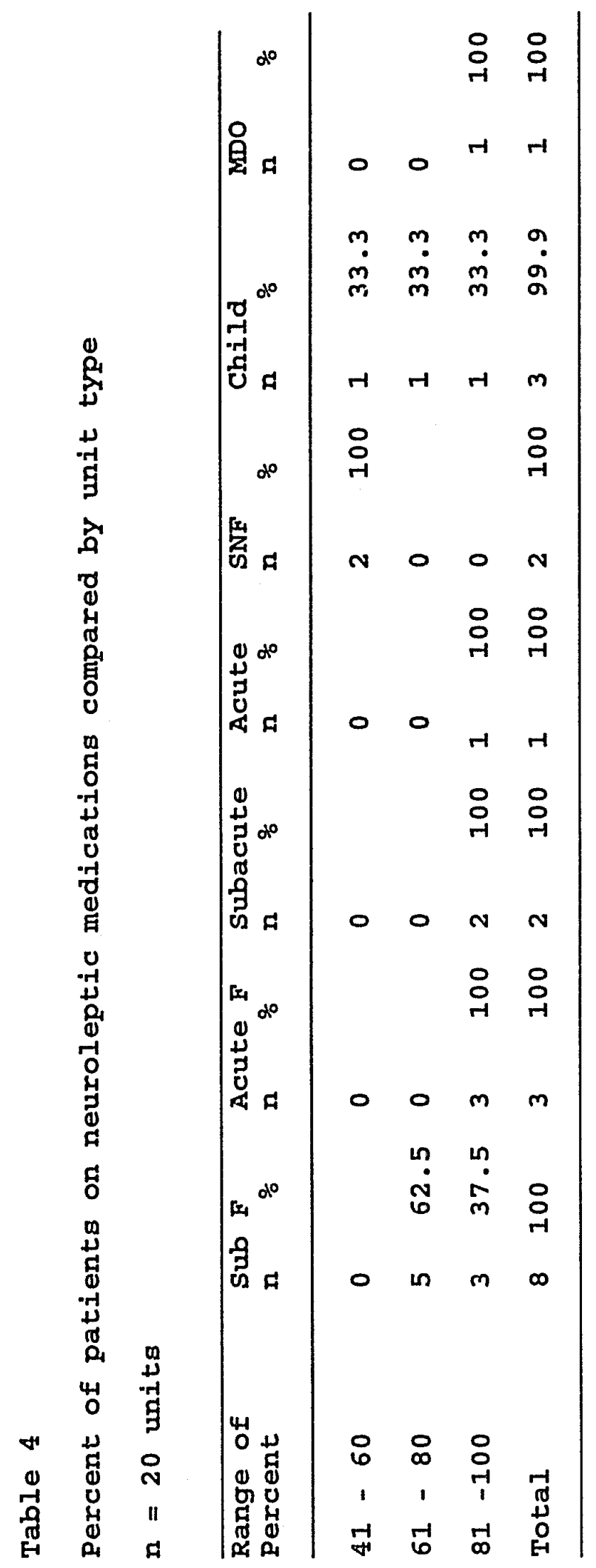




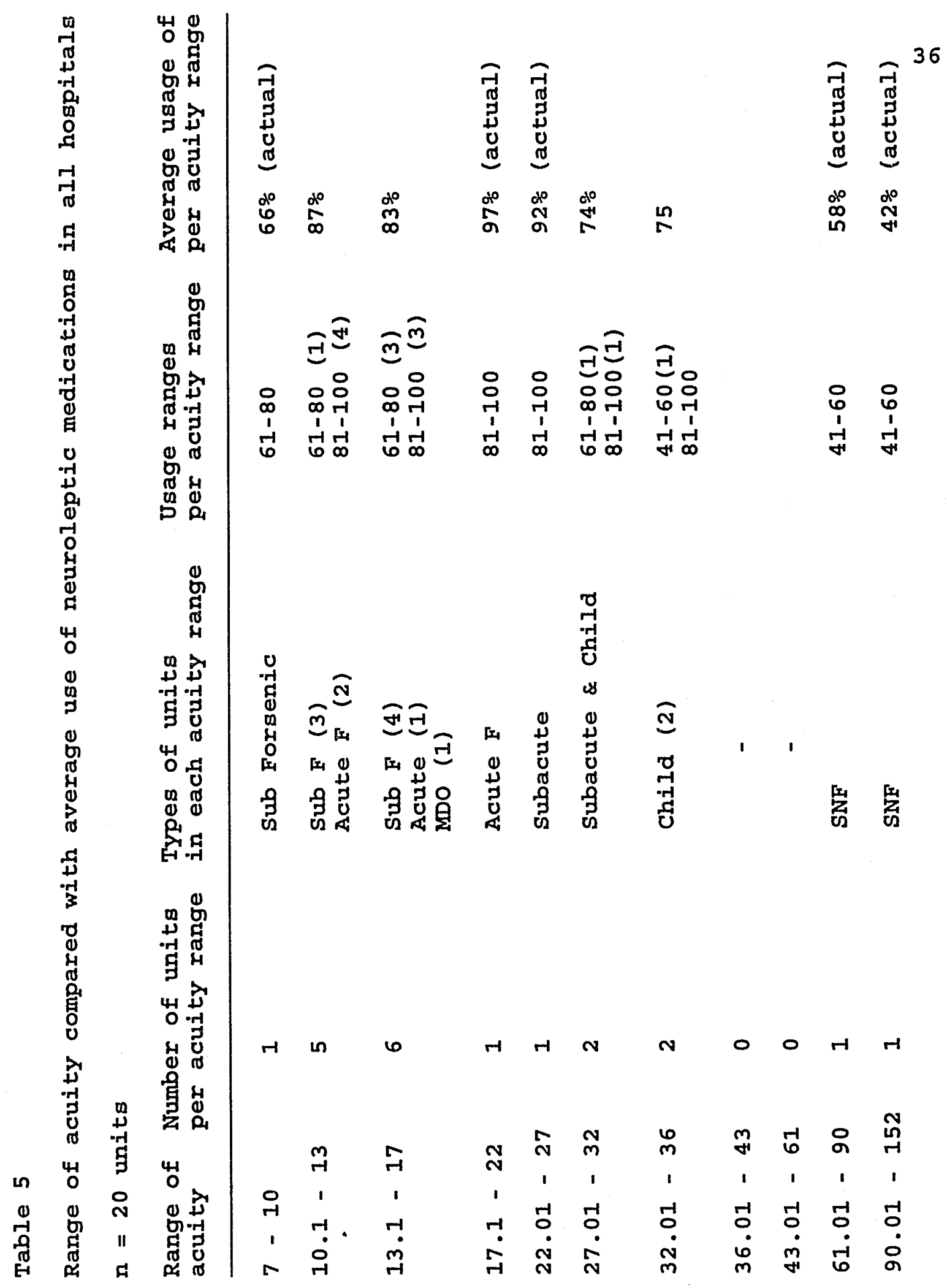


Antidepressant Medications

Table 6 reflects the use of Antidepressant medications in the total patient populations. Hospital A varies more in its usage than the other two hospital, with the lowest use at $7 \%$.

Table 6

Percent of all patients on antidepressant medications

Total \# patients Total \# on antidepressants (\%)

$\begin{array}{lccr}\text { All Hospitals } & 768 & 117 & \text { (15\%) } \\ \text { Hospital A } & 244 & 18 & \text { (7\%) } \\ \text { Hospital B } & 266 & 44 & \text { (17\%) } \\ \text { Hospital C } & 258 & 55 & \text { (21\%) }\end{array}$

In Table 7, all of the hospitals units usage ranges from $1 \%-30 \%$. Eleven (55\%) of the twenty units used a range from 1-10\%. Seven units (35\%) used a range from $21 \%-30 \%$ 
Table 7

Percent of patients on antidepressant medications in all hospitals/units

$n=20$ units

\section{Range of}

Percent

n $\%$

\begin{tabular}{rrr}
\hline $1-10$ & 11 & 55 \\
$11-20$ & 2 & 15 \\
$21-30$ & 7 & 35 \\
Total & 20 & 100 \\
\hline
\end{tabular}

In Table 8 the hospitals are compared in their use of antidepressant medications. Hospital $B$ and $C$ are similar in their usage percents. Hospital A differs with seven (87.5\%) of their units having a use of 1-10\%. 
Table 8

Percent of patients on antidepressant medications compared by hospital

$\mathrm{n}=20$ units

\begin{tabular}{llclcll}
\hline Range of & \multicolumn{2}{l}{ Hospital A } & \multicolumn{2}{l}{ Hospital B } & \multicolumn{2}{l}{ Hospital C } \\
Percent & n & $\%$ & n & $\%$ & n & $\%$ \\
& & & & & & \\
\hline $1-10$ & 7 & 87.5 & 2 & 33.3 & 2 & 33.3 \\
$11-20$ & 0 & & 1 & 16.6 & 1 & 16.6 \\
$21-30$ & 1 & 12.5 & 3 & 50 & 1 & 16.6 \\
$31-40$ & 0 & & 0 & & 2 & 33.3 \\
Total & 8 & 100 & 6 & 99.9 & 6 & 99.9 \\
& & & & & & \\
\hline
\end{tabular}

The percent of patients on antidepressants compared by unit type (Table 9) indicates that the subacute Forensic Units differ from the 1\%-10\% usage range found to be used by more than $50 \%$ of the units, with three (37.5\%) of their units usage from $21-30 \%$ and two (25\%) of the units in the $31-40 \%$ range.

The higher acuity ranges use less antidepressants than the lower acuities (Table 10). 


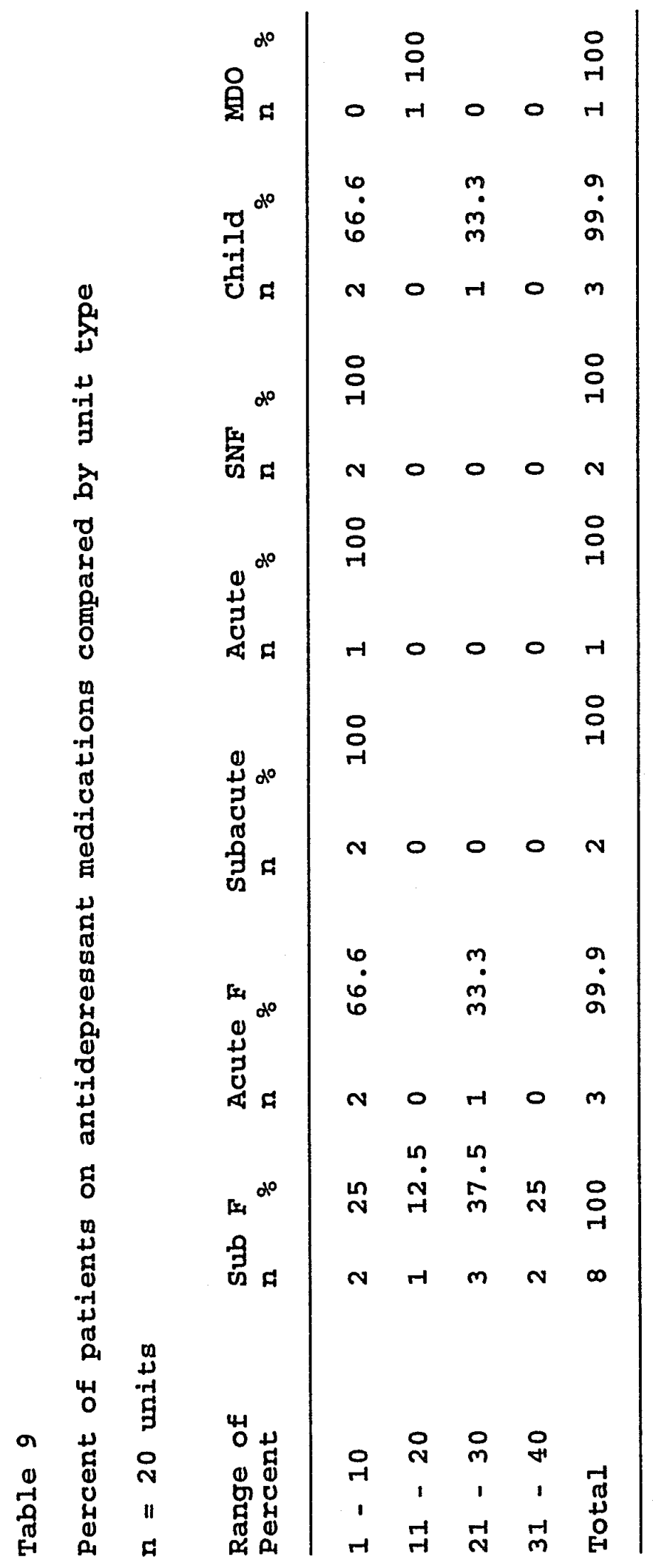




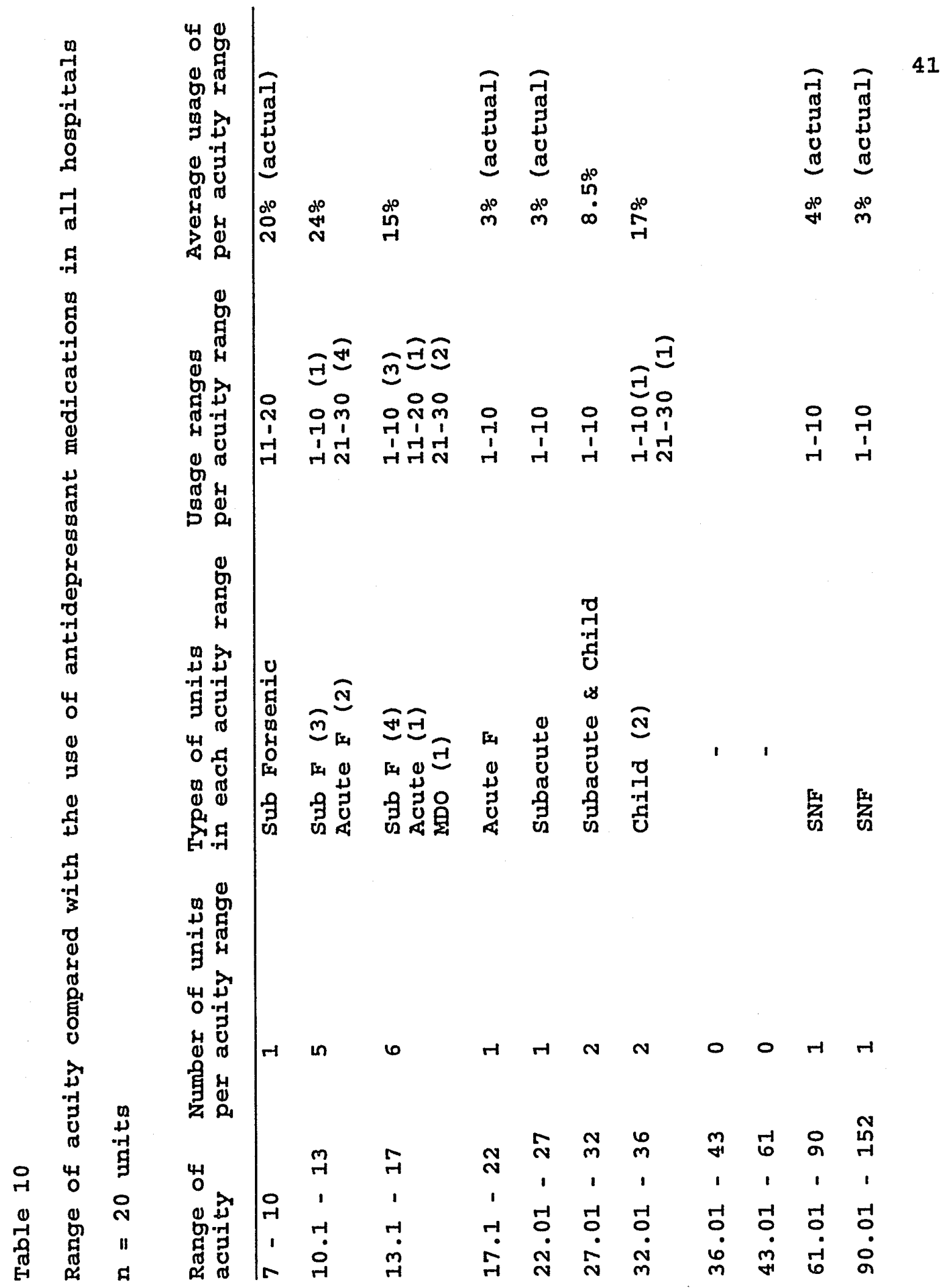




\begin{abstract}
Anxiolytic Medications
Anxiolytic medication usage for the total populations indicates that Hospital B has a lower usage than the other two hospitals (Table 11).

Table 11

Percent of all patients on anxiolytic medications
\end{abstract}

Total \# patients Total \# on anxiolytic (\%)

\begin{tabular}{llcl}
\hline All Hospitals & 768 & 201 & $(26 \%)$ \\
Hospital A & 244 & 87 & $(36 \%)$ \\
Hospital B & 266 & 25 & $(9 \%)$ \\
Hospital C & 258 & 89 & $(34 \%)$ \\
\hline
\end{tabular}

Table 12 shows the highest use range in all hospital units is $21 \%-40 \%$ with eight $(40 \%)$ of the units in this range. Within this medication category two units (10\%) had no usage and one unit had a use in the $61-80 \%$ range. 
Table 12

Percent of patients on anxiolytic medications in all hospitals/units

$n=20$ units

Range of

Percent

n 8

0

2

10

$1-20$

5

25

$21-40$

8

40

$41-60$

4

20

$61-80$

1

5

Totals

20

100

Table 13 compares the hospitals usage of this medication. The units that have no utilization are from Hospital B, with the majority of its units (50\%) falling between 1\%-20\% usage. Hospitals $A$ and $C$ are similar, with $50 \%$ of each of their units falling in the $21 \%-40 \%$ use range. 
Table 13

Percent of patients on anxiolytic medications compared by hospital.

$n=20$ units

\begin{tabular}{|c|c|c|c|c|c|}
\hline \multirow{2}{*}{$\begin{array}{l}\text { Range of } \\
\text { Percent } \\
0\end{array}$} & $\begin{array}{l}\text { Hospital A } \\
\mathbb{n}\end{array}$ & \multicolumn{2}{|c|}{$\begin{array}{ll}\text { Hospital } & \text { B } \\
n & \%\end{array}$} & \multicolumn{2}{|c|}{$\begin{array}{l}\text { Hospital } \\
n\end{array}$} \\
\hline & 0 & 2 & 33.3 & 0 & \\
\hline $1-20$ & 12.5 & 3 & 50 & 1 & 16.6 \\
\hline $21-40$ & 50 & 1 & 16.6 & 3 & 50 \\
\hline $41-60$ & 37.5 & 0 & & 1 & 16.6 \\
\hline $61-80$ & 0 & 0 & & 1 & 16.6 \\
\hline Total & 100 & 6 & 99.8 & 6 & 99.7 \\
\hline
\end{tabular}

Unit type comparison is shown in Table 14, indicating that the two units with no anxiolytic medication use are both Acute Forensic units. Another Acute Forensic unit had the highest usage range of $61 \%-80 \%$. Subacute Forensic units fall between $1 \%-40 \%$ use. Subacute and acute units fall into the $41 \%-60 \%$ range. The child/adolescent units range from $1 \%-40 \%$

The acuity range compared with the use of anxiolytic medications indicates the Subacute Forensic unit with the highest use falls in the fourth lowest acuity range (Table 15). 


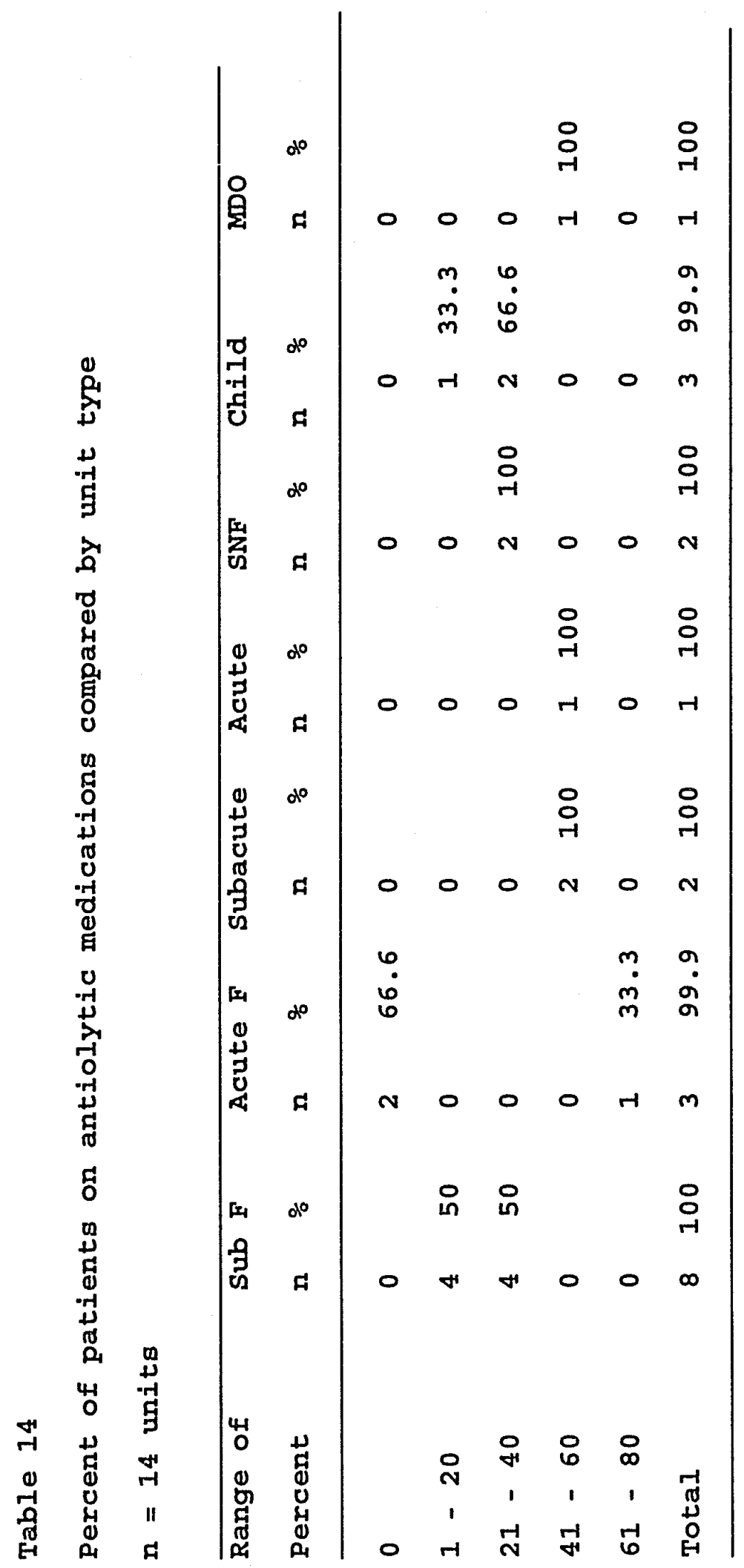




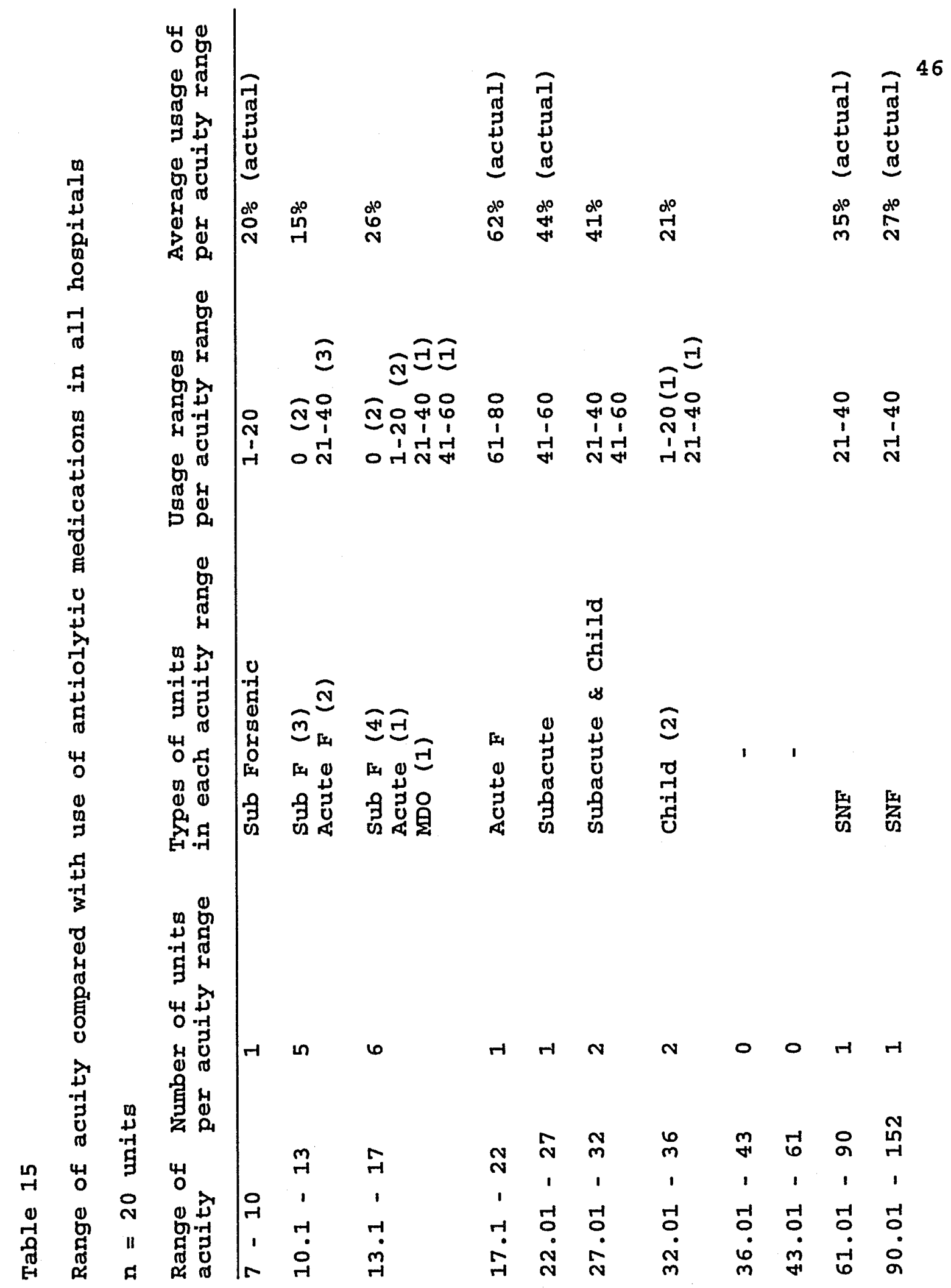


In two of the hospitals data were available to assess medications being used as sedative/hypnotics. Some of these medications are in the anxiolytic category. Table 16 reflects that data in the two hospitals by total

populations. It is obvious that one hospital apparently has a higher usage than the other.

Table 16

Percent of all patients on sedative/hypnotic medications

Total \# patients Total \# on sedative/hypnotics $(\%)$

Both Hospitals $502 \quad 95$

Hospital A

$244 \quad 94$

Hospital C

258

1

$(.4 \%)$

Table 17 shows that three (21\%) of the units in

Hospital A has a usage range of $41 \%-80 \%$. One unit has a range of $81 \%-100 \%$. 
Table 17

Percent of patients on sedatives/hypnotic medications in two hospitals/units

$\mathrm{n}=14$

Range of

Percent

n $\%$

7

50

$1-40$

3

21

$41-80$

3

21

$81-100$

1

7

Total

14

99

Table 18 indicates that the unit type using the highest percent of sedative hypnotics is one of the Subacute Units. The three units using the $41 \%-80 \%$ range includas the other Subacute, Acute, and SNF units. 


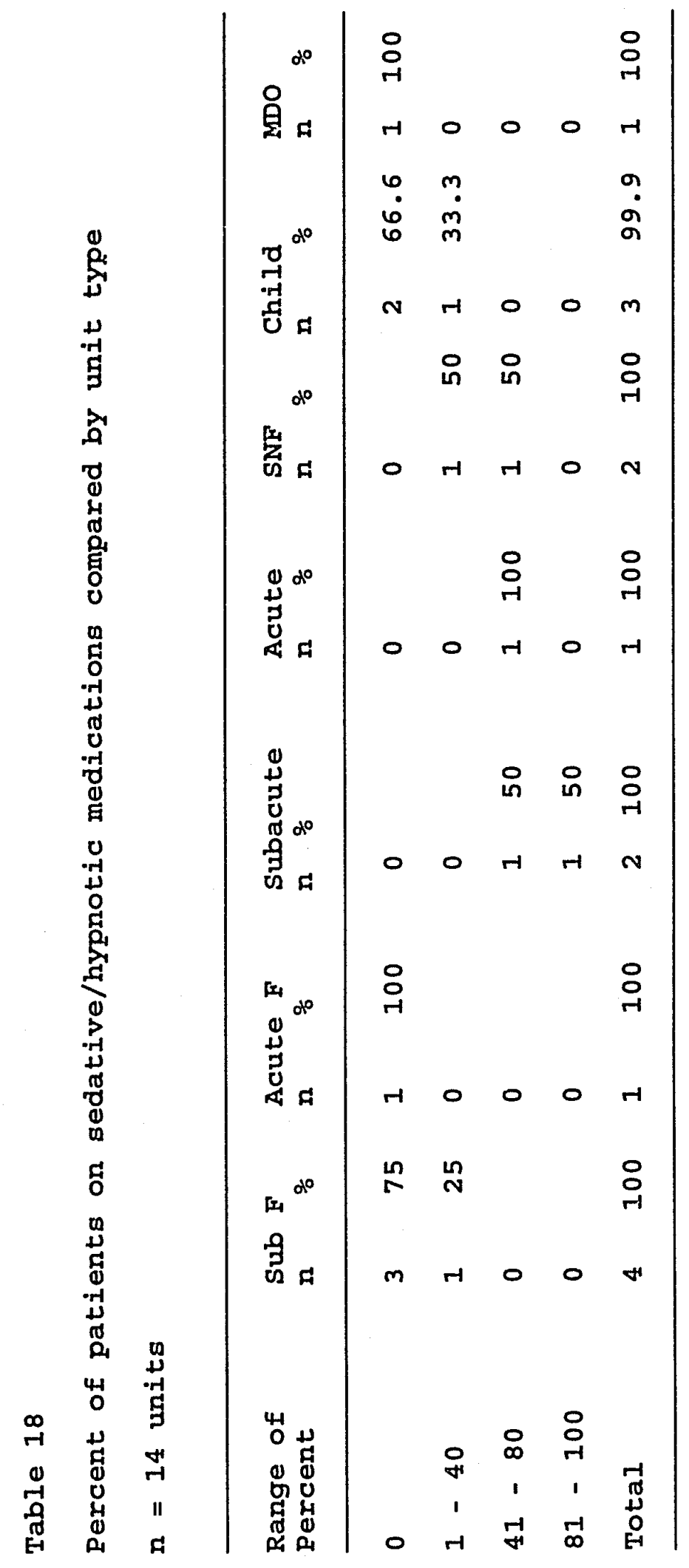




\section{Antimanic Medications}

The data on the antimanic medications were organized and analyzed in two different categories, lithium and the other antimanic medications, carbamazepine, clonazepam, and valproic acid. The reason for this was to analyze if all of the hospitals were similar in their use of the newer drugs. Lithium use in all patients between the hospitals varied very little, with Hospital B being slightly lower in use (Table 19).

Table 19

Percent of all patients on lithium

Total \# patients

All Hospitals

Hospital A

Hospital B

Hospital C
768

244

266

258
Total \# on lithium (\%)

172

57

42

73

Table 20 indicates that the units use of lithium ranged from $1 \%-60 \%$. The number of units within the first two ranges are identical. 
Table 20

Percent of patients on lithium in all hospitals/units $\mathrm{n}=20$ units

\section{Range of}

Percent

n $\%$

$1-20$

9

45

$21-40$

9

45

$41-60$

2

10

Total

20

100

The hospitals differed in their use ranges (Table 21). Hospital $A$ and $B$ highest use range was $1 \%-20 \%$. Hospital $C$ differed with its highest range being $21 \%-40 \%$. Both Hospital $A$ and $C$ had one unit in the range of $41 \%-60 \%$ usage, with none of the units in Hospital $B$ in this range. 
Table 21

Percent of patients on lithium compared by hospital

$\mathrm{n}=20$ units

\begin{tabular}{lcccccc}
\hline Range of & \multicolumn{2}{c}{ Hospital A } & \multicolumn{2}{c}{ Hospital B } & \multicolumn{2}{c}{ Hospital C } \\
Percent & n & $\%$ & n & $\%$ & $n$ & $\%$ \\
& & & & & & \\
\hline $1-20$ & 4 & 50 & 4 & 66.6 & 1 & 16.6 \\
$21-40$ & 3 & 37.5 & 2 & 33.3 & 4 & 66.6 \\
$41-60$ & 1 & 12.5 & 0 & & 1 & 16.6 \\
Total & 8 & 100 & 6 & 99.9 & 6 & 99.8 \\
\hline
\end{tabular}

In Table 22, the unit types are compared for their use of Iithium. Of the 8 subacute Forensic Units, 5 (62.5\%) fell in the range of $21 \%-40 \%$. The Acute Forensic had two units (66.6\%) in the 1\%-20\% range. The SNF units both fell in the $1 \%-10 \%$ range.

The highest acuity ranges shows the lowest usage of lithium (Table 23), with the remaining units falling into the common usage ranges. 


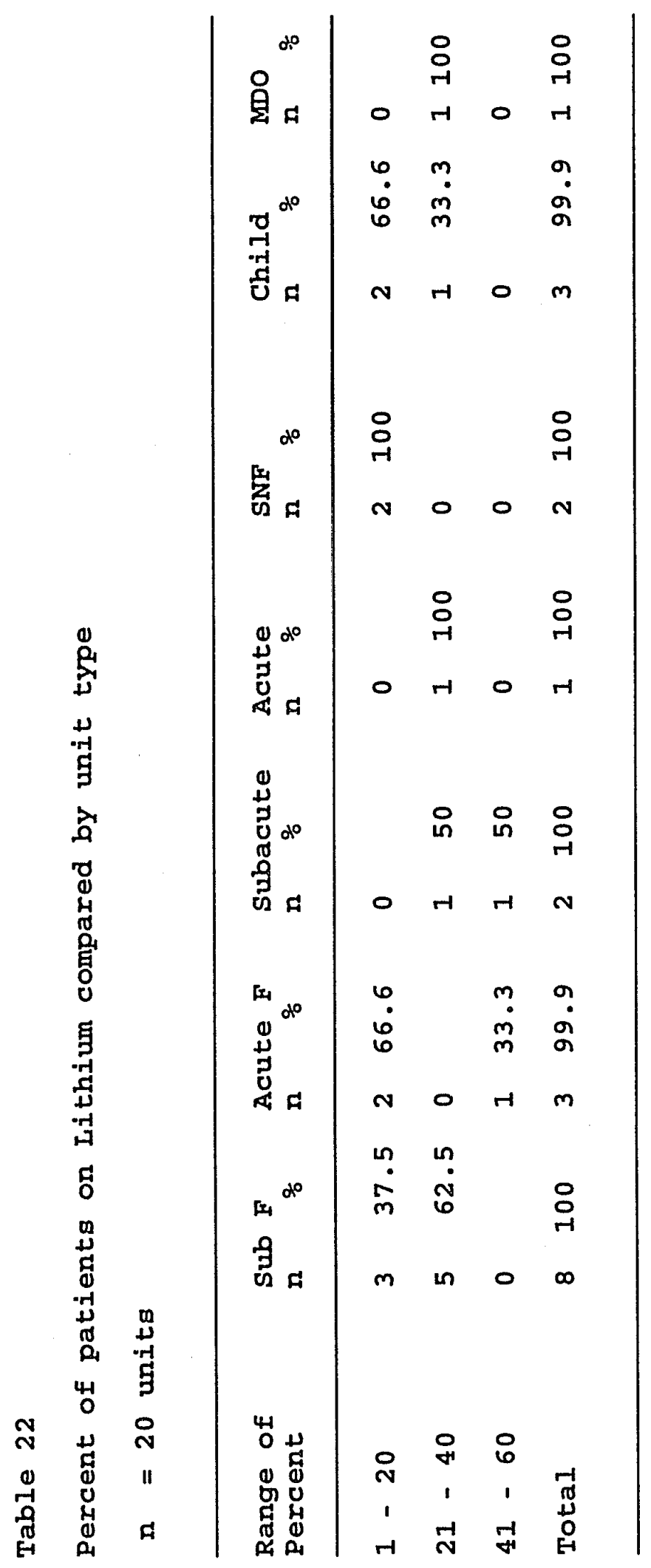




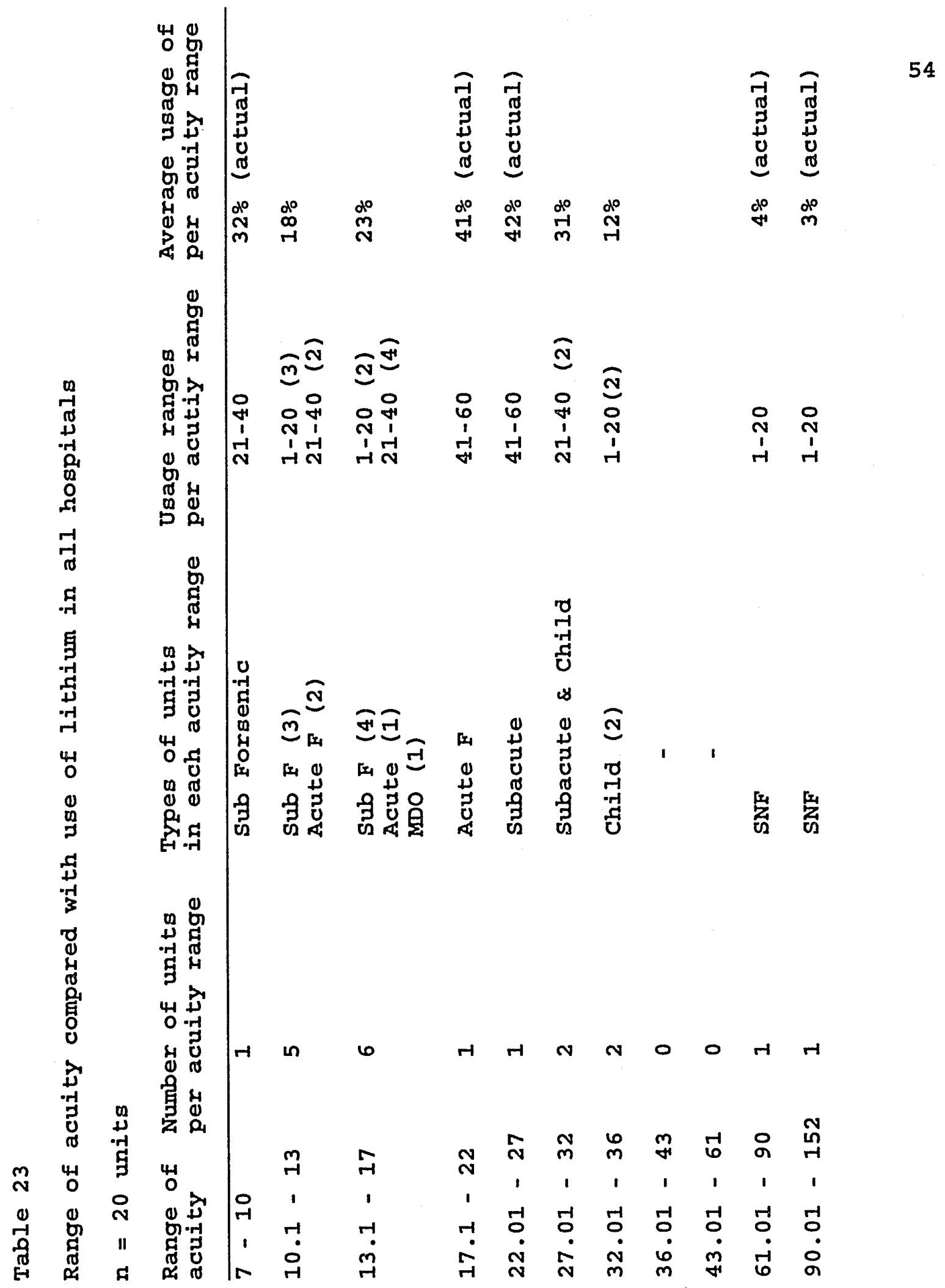


Table 24 shows no variation between the total population usage of other antimanic medications, carbamazepine, clonazepam, and valproic acid, in all hospitals. 
Table 24

Percent of all patients on other antimanic medications (carbamazepine, clonazepam, and valproic acid)

Total \# patients

All Hospitals

Hospital A

Hospital B

Hospital C
768

244

266

258
Total \# on antimanic

212

60

78

74
(29\%)

The use of other antimanic medications in all hospital units reflects ranges from $1 \%-60 \%$, the same range as lithium use; except one unit shows no usage of the other antimanic medications. The majority of the units, 11 units (55\%), use a range of $21 \%-40 \%$ (Table 25 ). 
Table 25

Percent of patients on other Antimanic Medications (carbamazepine, clonazepam, and valproic acid)

in all hospitals/units

$\mathrm{n}=20$ units

Range of

Percent

n

$\%$

\begin{tabular}{lrc}
0 & 1 & 5 \\
$1-20$ & 5 & 25 \\
$21-40$ & 11 & 55 \\
$41-60$ & 3 & 15 \\
Total & 20 & 100 \\
\hline
\end{tabular}

Hospitals $B$ and $C$ were similar in that $50 \%$ of the units or higher fell in the $21 \%-40 \%$ range of use (Table 26). Hospital A's units varied between all of the ranges, with one unit not using any of these medications. Hospital $C$ had no units in the range of $41 \%-60 \%$. 
Table 26

Percent of patients on other Antimanic Medications (carbamazepine, clonazepam, and valproic acid) compared by hospital

$n=20$ units

\begin{tabular}{lllllll}
\hline Range of & \multicolumn{2}{l}{ Hospital A } & \multicolumn{2}{c}{ Hospital B } & \multicolumn{2}{c}{ Hospital C } \\
Percent & $n$ & $\%$ & $n$ & $\%$ & $n$ & $\%$ \\
& & & & & & \\
\hline 0 & 1 & 12.5 & 0 & & 0 & \\
$1-20$ & 2 & 25 & 2 & 33.3 & 1 & 16.6 \\
$21-40$ & 3 & 37.5 & 3 & 50 & 5 & 83.3 \\
$41-60$ & 2 & 25 & 1 & 16.6 & 0 & \\
Total & 8 & 100 & 6 & 99.9 & 6 & 99.8 \\
& & & & & & \\
\hline
\end{tabular}

Table 27 compares use of the other antimanic medications among unit types and reflects that one unit with no use is a Child/Adolescent unit, while the other two Child/Adolescent units show usage percent in the ranges of $21 \%-40 \%$ and $41 \%-60 \%$. 


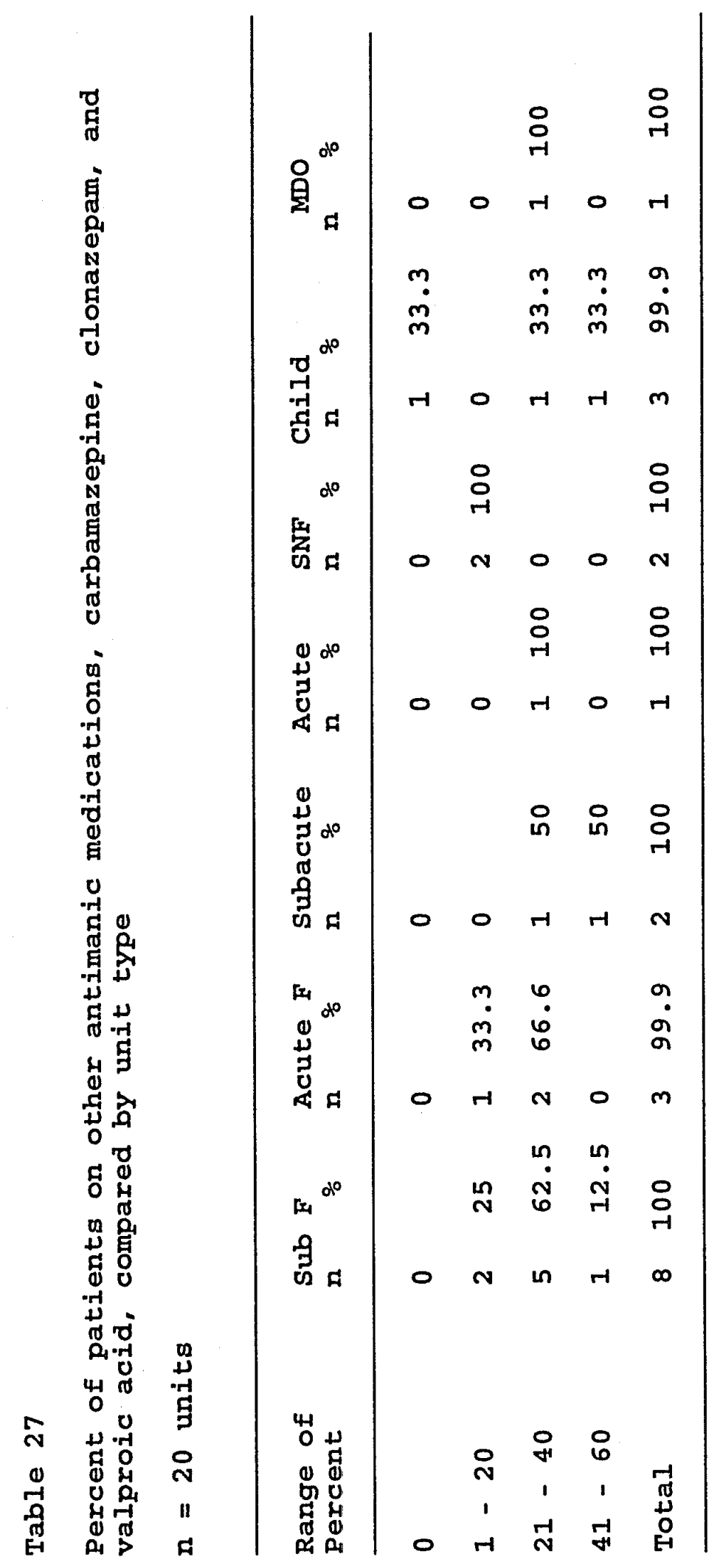


The higher acuity ranges show a lower use range for the other antimanic medications than the lowex acuity ranges (Table 28). However, the higher acuity ranges are actually higher in their use of the other antimanic medications than their use of lithium (Tables 23 and 28). 


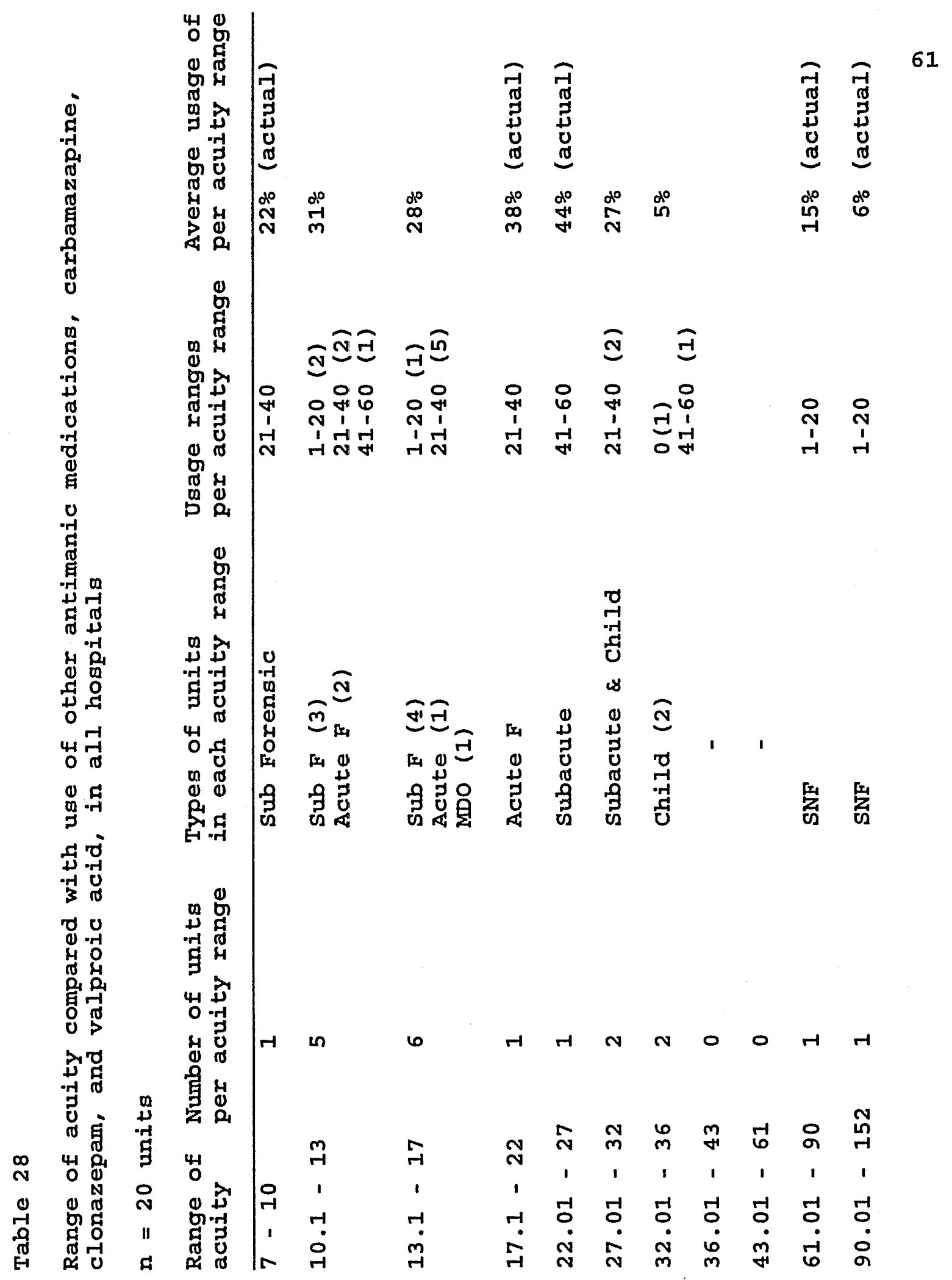


Summary

Analysis of the data revealed that neuroleptics is the highest used medication category with $73 \%-87 \%$ of the total population on these medications. Anxiolytic medications was the second most frequently reported category with $9 \%-36 \%$ of the total populations prescribed this category. The other categories in order of higher use to lower use includes the antimanic medications, excluding lithium (25\%-29\%), lithium $(16 \%-28 \%)$, and finally the lowest use range category of antidepressants $(7 \%-21 \%)$.

Neuroleptic use in most of the individual units was 81\%-100\%. The majority of the individual units fell into the following use range for each of the other categories as follows: anxiolytic $(21 \%-40 \%)$, antimanic $(21 \%-40 \%)$, lithium $(1 \%-40 \%)$, and antidepressants $(1 \%-10 \%)$.

Comparison between the hospitals showed that Hospital A differed from the other two hospitals in its usage in most categories. Hospital A had the lowest use in the two categories of neuroleptic and antidepressant medications. It had the highest use in the anxiolytic category and the sedatives/hypnotic medications. The antimanic medication category showed Hospital $A$ had a different usage pattern than the other two hospitals. Hospitals $A$ and $B$ were more similar in their lithium use; Hospital $C$ was different, with the majority of their units using the $21 \%-40 \%$ range. 
Comparison between the unit types showed that the unit types were similar in their usage of the medication categories, except for the Child/Adolescent units in neuroleptic and antimanic use, the Subacute Forensic units in antidepressant, anxiolytic and antimanic medication use, and the Acute Forensic units in anxiolytic medications and lithium use.

The highest acuity ranges had the lowest use in the categories of neuroleptic, antimanic, lithium, and antidepressant medications. They were not lower in their anxiolytic use, but were similar in use to the lower acuities. 


\section{Chapter 5}

\section{CONCLUSIONS AND RECOMMENDATIONS}

The objective of this study was to describe and analyze the types of psychotropic medications being prescribed at the unit level in three California state Mental Health Hospitals. The research questions developed to achieve the study objective included:

1. What are the categories of psychotropic medications being prescribed in three of the California State Hospitals, Department of Mental Heal th?

2. What is the usage of the categories in the total population, in each hospital, in all units across the hospitals, and among unit types?

3. Is the percent of patients on each category similar in each of the hospitals, in all units across the hospitals, and among unit types?

4. What is the usage of the categories in the various acuity levels within the three hospitals and the different unit types?

Considering the profound effect that psychotropic medications have had on the treatment of the mentally ill, it would appear reasonable to begin to assess the medication usage across units and institutions. If the categories of medications being prescribed in a unit change, it may 
reflect the type of patient being treated and therefore the staffing of that unit.

Once this type of data is collected routinely during staffing studies, other trends and practices could be studied, such as the relationship between workload and type of medication prescribed.

\section{Conclusions}

All four categories of psychotropic medications (neuroleptic, antidepressant, anxiolytic, and antimanic) were found to be prescribed at the three state Hospitals. Appendix $\mathrm{E}$ is a listing of the specific medications prescribed by category. For the purpose of this study, the antimanic category was subdivided into two, lithium and other antimanic medications.

Neuroleptic medications, $81 \%$ use by the total population, were the highest prescribed medication category. The neuroleptic medications are the category that marked a beginning in a new era of mental health treatment. "The new drugs were revolutionary because they worked. Previously, effective treatments for severe mental illness had been virtually unknown" (Lickey \& Gordon, 1983, p. 3). "Thorazine transformed the atmosphere in the disturbed wards. Physical restraints were a thing of the past--and the milieu became therapeuticl" Thorazine "improved psychiatric therapy most dramatically where it was most 
needed, in large mental hospitals." Its use enabled patients to be treated as outpatients (Caldwell, 1970, p. 12). Since patients can now be treated effectively on an outpatient basis, the only reasons to admit them to a hospital is due to a psychotic crisis, an inability to manage their symptoms on an outpatients basis, or due to a court order, because they have committed a crime. This last type of patient is admitted to forensic hospitals. Therefore, it was an expected finding that the neuroleptic category is the category most prescribed.

Anxiolytic medications, the second most prescribed category was only used by $26 \%$ of the total population. There may be three reasons for the low use. Anxiolytic (antianxiety) medications are used for the primary purpose of reducing or controlling anxiety and agitation (Murrey, 1991, p. 5). Most symptoms exhibited in anxiety, such as tension, fear, dread, or terror, as well as, the other uses of anxiolytic medications, such as panic-attack disease, restlessness, insomnia, tension, senile agitation, muscle disorders, somatoform disorders, personality disorders, acute alcoholism and hysteria can be treated on an outpatient basis. Only a few patients would need to be admitted to a hospital for primary treatment of anxiety, which accounts for the one reason for a low use. Another reason it is expected to find less of these medications 
prescribed is due to the fact that all of the anxiolytic medications are capable of being used as a sedative-hypnotic and it is not recommended to use them for insomnia in mental illness; "insomnia can and should be treated as part of the larger problem, and sedative antipsychotics or antidepressants may be given at bedtime to accomplish this purpose" (Wilson \& Kneisl, 1988, p. 883). The final reason for the low use may be directly related to the fact that these drugs tend to be drugs of abuse and the patient population has some history of drug abuse.

Iithium was prescribed for $22 \%$ of the total population, and the other antimanic medications, carbamazepine, clonazepam, and valproic acid, were prescribed for $28 \%$. Antimanic medications are "useful for the management of acute manic psychosis and certain schizoaffective conditions and as a prophylactic agent in selected bipolar, unipolar depressions and mania" (Murrey, 1991, p. 5). This finding would indicate that patients with these disorders are effectively treated as outpatients and only are admitted if there is a crisis with this disorder or they become psychotic.

Antidepressant medications were prescribed for $15 \%$ of the total population. Antidepressant medications are used for the alleviation of symptoms of depression, such as a depressed mood of two weeks duration or longer, in addition 
to other symptoms such as loss of energy and interest in normal activities, sleep and eating disturbances, inability to concentrate, feelings of guilt, and psychomotor retardation or agitation, or suicide ideation. similar to anxiety, only a few patients would be admitted to a hospital for primary treatment of depression, therefore the amount of this category prescribed would be expected.

There were variations in the use of the medications among the hospitals and units.

In comparison with the other two hospitals, Hospital A differed in its usage in three of the categories. Hospital A used a lower percent of both neuroleptic and antidepressant medications and a higher percent of the anxiolytic medications. Since both Hospitals $B$ and $C$ included forensic units, it would be expected that they would be more similar than Hospital A, which had no forensic study units. One variation in use where no explanation seems evident is that Hospital A's usage of the antimanic medications was similar to Hospital B.

In only two of the Hospitals, $A$ and $C$, could a comparison be made in regard to the use of sedative/hypnotic medications, a subgroup of the anxiolytic category, due to differences in the data. It was found that Fospital A had a $39 \%$ overall use of sedative/hypnotic medications and Hospital $C$ had a 3\% use. One explanation for the low use of 
these medications at Hospital $C$ is that the patient population is primarily a forensic population.

In comparison with the unit types, variations were noted in the Child/Adolescent units with neuroleptic and other antimanic medication use, the Subacute Forensic units in antidepressant use, and the Acute Forensic units in anxiolytic use.

There were three Child/Adolescent units in the study and all were located in one hospital. Neuroleptic and other antimanic medication use was different in each unit. In one of the units, there was no use of the other antimanic medications.

Each of two hospitals has four subacute Forensic units. The variation in the use of antidepressants included differences in use among the subacute Forensic units, as well as differences from the other types of units. The majority of the other type of units use a $1 \%-10 \%$ range of antidepressants; the subacute Forensic units fell into all ranges.

In the Acute Forensic units located in two of the hospitals, usage of anxiolytic medications varied. Two units in one hospital had no use of anxiolytic medications and the third unit located in another hospital was the only unit to have a high usage range $61 \%-80 \%$. 
other reasons for these variations include physician practice patterns and patient diagnosis. Physician's prescribing practice is based on his/her training and experience and will vary among practitioners. Patient's diagnosis, which will determine classification of medication prescribed, is also dependent on physician's training and experience.

It is difficult to draw conclusions as to the significance of these variations or the reasons for them. The data are limited and insufficient to perform a statistical analysis to determine if the variations are statistically significant.

The data suggest questions for future research such as: 1) What is the natural variation that can be expected between units and hospitals in the types of psychotropic medications used? 2) What are the factors related to the variation? 3) How do the following variables relate to the variations: $M D$ education, background, knowledge of pharmacology, knowledge of the pharmacists and the part they play in the interaction with medical staff in prescribing medications, differences in patients, such as, ethnicity, educational background, diagnosis, type of admission, and acuity and, 4) How does the variation affect workload?

The patient population in this study had been admitted to a hospital and a large portion were admitted through a 
court order, related to crimes, or on non-voluntary status related to being gravely disabled. Neuroleptic medications were prescribed for $81 \%$ of the population. These facts indicate that this population is unable to provide self care. Self care has been defined by Dorothy Orem (1980) as "...the practice of activities that individuals initiate and perform on their own behalf in maintaining life, health, and well being" (p. 35). "When a change in health state brings about total or almost total dependence on others for the needs to sustain life or well-being, the person moves from the position of self-care agent to that of patient or receiver of care" (Orem, 1980, p. 49). Self care can be viewed on a continuum: at one end are individuals who can provide total care for themselves, with no need of nursing care; at the other end of the continuum are individuals who cannot provide self care and must rely on nursing to care for their needs. It would appear that the need for nursing care and thus nursing time is increased as individuals move closer to the end of the continuum where they cannot provide their own care.

Nursing actions performed to deliver care or enable the patient to render their own self care translates into workload activities. This means that the activity occurs as a result of the nurse or care giver providing a certain amount of work and time to perform the activity. 
There are nursing activities that are necessary for effective use of the psychotropic medications, including assessment and monitoring of patients for effectiveness and side effects, administration, interventions for side effects and patient teaching. This would translate into a certain amount of workload, considering that $81 \%$ of the population is on neuroleptic medications. The question remains as to what the correlations are between the medications being prescribed and nursing worlsload.

The comparison of medication use with the unit's acuity was inconclusive. The highest acuity ranges were the SNF units, which had the lowest use of neuroleptic, antimanic, Iithium, and antidepressants medications. The lower use of these medications and the reason for a higher acuity is probably attributed to the older patient population. The patients have an increased need for total care, which increases the acuity. They are frail and less tolerant of these types of medications, which is demonstrated by the low use. However, there are questions that arise from the data, including: How is the caregiver time required by patients related to the medications that are being used in their treatment? Are the workload issues in regard to the categories and number of medications patients receive taken into account due to current method of assessing workload? Does an increase in the categories of medications decrease 
the workload due to having patients who are more in control or does it increase the workload, dependent on the type of medications, since some include the need for diagnostic monitoring and increase teaching to the client?

In summary, the data obtained did achieve the stated purpose of the study, to begin to assess drug usage across units and hospitals, and it answered the research questions. However, the data and research raised many more questions that need to be answered.

\section{RECOMMENDATIONS}

Based on the findings of this study, it is recommended that:

1. All future staffing studies include drug usage information that is designed to capture consistent and welldefined data elements.

2. A methodology be developed and implemented to correlate the category of drug use with workload.

3. Include patient diagnosis in the studies.

4. Drug use/workload data be shared between all Mental Health Hospitals in each state and across the country to begin to gather enough data to be statistically significant and to be able to define trends and practices that can be studied. The final outcome of these studies may include clinical pathways in the treatment of mental illness that may produce cost savings, or more efficient decision making 
regarding the type and amount of medications given and appropriate staffing to provide the care necessary. 
REFERENCES 


\section{REFERENCES}

Appleton, w. (1988). Practical clinical psychopharmacology (3rd ed.). Baltimore, MD: Williams \& Wilkens.

Auger, J. A., \& Dee, V. (1983). A patient classification system based on the behavioral system model of nursing: Part 1. Journal of Nursing Administration, 13, (4), 3843.

Caldwel1, A. (1970) . Origins of psychopharmacology. Springfield, Illinois: Charles C. Thomas, Publisher. California State, Department of Mental Health, Health and Welfare Agency, (1979, April). State hospital staffing standards.

Freund, I., Connolly, P., Diasio-Serret, K., \& Parker, H. (1992). State hospital level of care, staffing standards study. San Jose, CA.: San Jose State University, Department of Industrial \& Systems Engineering .

Haber, J., Hoskins, P. P., Leach, A. M., \& Sideleau, B. F. (1987) . Comprehensive psychiatric nursing. (3rd ed.). New York: McGraw-Hill Book Company. Harris, E. (1981). Antipsychotic medications. American Journal of Nursing, $81,(7), 1316-1323$.

Harris, E. (1981). Lithium. American Journal of Nursing. 81, (7), 1310-1315. 
Harris, E. (1988). The antipsychotic. American Journal of Nursing, 88, (11), 1508-1518.

Lickey, M. E., \& Gordon, B. (1983). Drugs for mental illness, a revolution in psychiatry. New York: W. H. Freeman and Company. Mason, A. S., \& Granacher, R. P. (1980). Clinical handbook of antipsychotic drug therapy. New York: Brunner/Mazel, Publishers.

McEvoy, G., Iitvak, R., Welsh, O., Dewey, D., Fong, P., Ford, M., Douglas, P., Shannon-Lass, E., Epstein, M., Rester, I., Campbell, J., Fredrickson, M., \& Ziegler, K. (Eds.) (1993). American Hospital Formulary Service, Drug Information. 93. Bethesda, MD; American Society of Hospital Pharmacists, Inc.

Murrey, C. (1991, July 15). Psychotropic medication guidelines (Special order DSH - 134). Sacramento, CA.: Department of Mental Health, Division of State Hospitals.

New York state, Office of Mental Health. (1983). Status report: Development of post staffing standards for adult inpatient services. Albany, New York. Nutter, R. E. \& Marlow, H. A. (1985, April). Staffing standards - Florida's State Mental Health Hospitals. Gainesville, FL: Florida Department of Health and Rehabilitative Services. 
Orem, Dorothea E. (1980) - Nursing: Concepts of practice. (2nd ed.). New York: McGraw Hill Book Company. Sullivan, J. I. and Sullivan, P. D. (Eds.) (1984). Biomedical psychiatric therapeutics. Boston: Butterworth Publishers.

Taber, C. W. (1965). Taber's cyclopedic medical dictionary. (10th ed.). Philadelphia: F.A. Davis Company. Willcutt, H. C. \& Hart, R. V. (1989, September). Administrative and clinical staffing standards. Alabama: Alabama state Mental IlIness Facilities, Office of the Associate Commissioner for Mental IIlness. Wilson, H. S. \& Kneisl, C. R. (1988). Psychiatric nursing. (3rd ed.). Menlo Park, CA: Addison-Wesley Publishing Company. 
BIBLIOGRAPHY 


\section{BIBLIOGRAPHY}

Alward, R. R. (1983). Patient classification systems: The ideal vs. reality. The Journal of Nursing Administration, $13,(2), 14-19$.

Auger, J. A. \& Dee, V. (1983). A patient classification system based on the behavioral system model of nursing: Part 2. Journal of Nursing Administration, $13,(5), 18-$ 23.

Barchas, J. D., Berger, P. A., Ciaranello, R. D., \& Elliot, G. R. (1977) . Psychopharmacology, from theory to practice. New York: Oxford University Press. Battista, O. A. (1960). Mental drugs: Chemistry's challenge to psychotherapy. New York: Chilton Company. Beitman, Bernard \& Klerman, Gerald (Eds.) (1984). Combining psychotherapy and drug therapy in clinical practice. New York: Spectrum Publications, Inc. Boettcher, E. G. \& Alderson, S.F. (1982) . Psychotropic Medications and the Nursing Process. Journal of Psychosocial Nursing and Mental Health Services, 20, (11), $12-16$.

Boettcher, E. G. (1983) . Preventing violent behavior. Perspectives in Psychiatric Care, 22, (2), 54-58. Burrows, G. D., Norman, T. R., \& Davies, B. (Eds.) (1984). Antianxiety agents. (Vol. 2). New York: Elsevier. 
Burrows, G. D., Norman, T. R., \& Davies, B. (Eds.) (1985). Antipsychotics. (Vol. 3). New York: Elsevier. Clark, w. G. \& del Guidice (Eds.) (1978). Principles of psychopharmacology. New York: Academic Press. Decker, P. J. \& Sullivan, E. J. (Eds.) (1992). Nursing adminigtration, A micro/macro approach for effective nurse executives. Norwalk, CT.: Appleton \& Lange. Denber, Herman C. B. (1979). Textbook of clinical psychopharmacology. New York: stratton Intercontinental Medical Book Corporation.

Essman, Walter \& Valzelli, L. (Eds.) (1975). Current developments in psychopharmacology. $\underline{2}$. New York: Spectrum Publications.

Giannini, A. J. (Ed.) (1986). The biological foundations of clinical psychiatry. New York: Elsevier Science Publishing Company, Inc. Gillies, D. \& Lader, M. (1986). Guide to the use of psychotropic drugs. New York: Churchill Livingstone. Giovannetti, P. (1979). Understanding patient classification systems. Journal of Nursing Administration, 9, (2), 4-9. Kolb, Lawrence. (1977). Modern clinical psychiatry. Philadelphia: W. B. Saunders Company. 
Neizo, B. \& Murphy, M. K. (1983). Medication groups on an acute psychiatric unit. Perspectives in Psychiatric Care, 22, (2), 70-73.

Shader, Richard I. (Ed.) (1975). Manual of psychiatxic therapeutics. Boston: Little, Brown and Company. Treanor, J. J. \& Cotch, R. E. (1990). Staffing of adult psychiatric inpatient facilities. Hospital and Community Psychiatry, 41, (5), 545-549.

Wiener, M. B. \& Pepper, G. A. (1985) - Clinical pharmacology and therapeutics in nursing. (2nd ed.). New York: McGraw-Hill Book Company. 
APPENDIX A

Neuroleptic Medications 
Neuroleptic Medications

GENERIC NAME

Phenothiazine

Aliphatics

chlorpromazine

triflupromazine

Piperidines

thioridazine

mesoridazine

piperacetazine

Piperazines

trifluoperazine

acetophazine

fluphenazine

fluphenazineenanthate

fluphenazinedecanoate perphenazine procholperazine butaperazine carphenazine

Thioxanthenes cholprothixene thiothixene

Butyrophenones haloperidol

Dihydroindolones molindone

Dibenzoxapines Ioxapine

Diphenylbutyl

piperdines

penfluridol

pimoside

clozapine
TRADE NAME

Thorazine

Vesprin

Mellaril

Serentil

Quide

Stelazine

Tindal

Prolixin

Prolixin-

Prolixin-

Decanoate

Trilafon

Compazine

Repoise

Proketazine

Taractan

Navane

Haldol

Iidone

Moban

Loxitane

Daxolin

both

experimental

Clozaril 
APPENDIX B

Antidepressant Medications 
Antidepressant Medications

GENERIC NAME

Tricyclics imipramine desipramine amitriptline nortriptyline doxepin protriptline trimipramine amoxapine

Tetracyclics maprotiline

Triazolopyridine trazodone

Monoamine Oxidase Inhibitors

Hydrazines isocarboxazid phenelzine

Nonhydrazines tranylcypromine Pargyline

*Used as an antihypertensive.
TRADE NAME

Presamine, Tofranil Norpramin, Pertofrane Amitril, Elavil, Endep Aventyl, Pamelor Adapin, Sinequan Vivactil

Surmontil

Asendin

Ludiomil

Desyrel

Marplan

NardiI

Parnate

Eutonyl * 
APPENDIX C

Anxiolytic Medications 
Anxiolytic Medications

GENERIC NAME

Antihistamines

hydroxyzine hydrochloride

hydroxyzine pamoate

Barbiturates

amobarbital

butabarbital

phenobarbital

Propanediols

meprobamate

tybamate

beta-adrenergic blockers

propranolol hydrochloride

\section{Benzodiazepines}

alprazolam

chlordiazepoxide

clorazepate dipotassium

diazepam

flurazepam

lorazepam

temazepam

triazolam
TRADE NAME

Atarax

Vistaril

Amytal

Butisol

Luminal

Miltown

Equanil

solacin

Tybatran

Inderal

Xanax

Librium

Tranxene

valium

Dalmane

Ativan

Restoril

Halcion 
APPENDIX D

Human Subjects-Institutional Review Board Letter of Approval 


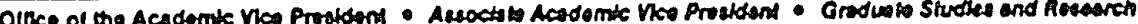

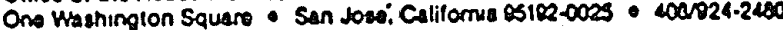

To: Susan Henderson, Nursing

17749 Pesanta Road

Sallnas, CA 93906

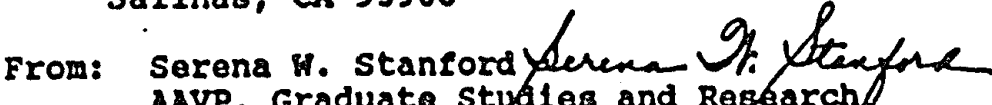

AAVP, Graduate Styales and Regearch

Date: June 18,1992

The Human subjects-Institutional Review Board has revlewed and approved your request for exemption from Human Subjects Reviou for the proposed study entitled: ..

"A Descriptive study of the Categories of Psychotropic Drugs Utilized by Inpatients in the study Units of Three of the Calleornia state Mental Health Facilities"

You may procoed with this study without further roview by the Human subjects-Institutional Rovlew Board.

I do caution you, however, that Foderal and state otatutas and University pollcy roquire investigatore conducting research under exempt categorlea to be knouledgeable of and comply with Federal and state rogulations for the protection of human subjects in research. Thls includes providing necessary information to enable people to make an Informed decision regarding participation in your study. Further, whenavar people participate in your research as human subjects, they ghould be appropriataly protected eroa riak. This includes the protection of the coneidentiality of all data that may bo collected fros the subjects. If at any time a subject becomes Injured or complains of infury, you must notify Dr. Serena stanford immodiatoly. Infury includes but is not 1 lolted to bodily harr, paychological trauna and release of potentlally damaging personal information.

Please also be advised when people particlpate in your research as human subjecte, each bubject needs to bo fully intormed and aware that their particlpation in your research profect 18 voluntary, and that he or she may withdraw frow the project at any time. Further, a subject's participation, refusal to participate or withdrawal will not affect any services the subject is recalving or will recelve at the institution in which the research is boing conducted.

If you have questlons, please contact wo at $408-924-2480$.

cc: shyll1s . Connolly, Nurging 
APPENDIX E

Psychotropic Medications Used in the Study Units 
Rsychotropic Medications Used in the Study Units

I. Neuroleptic Medications

GENERIC NAME
chlorpromazine
triflupromazine
thioridazine
trifluoperazine
fluphenazine
perphenazine
thiothixene
haloperidol
Dihydroindolones
molindone
loxapine
clozapine

TRADE NAME

Thorazine

Vesprin

Mellaril

Stelazine

Prolixin

Trilafon

Navane

Haldol

Moban

Loxitane

Clozaril

II. Antidepressant Medications

GENERIC NAME

$$
\begin{aligned}
& \text { imipramine } \\
& \text { desipramine } \\
& \text { amitriptline } \\
& \text { nortriptyline } \\
& \text { doxepin } \\
& \text { amoxapine } \\
& \text { trazodone } \\
& \text { fluoxetine }
\end{aligned}
$$

III. Anxiolytic Medications

\section{GENERIC NAME}

hydroxyzine hydrochloride alprazolam clorazepate dipotassium lorazepam buspirone
TRADE NAME

Trofranil Norpramin Elavil Aventyl Sinequan Asendin Desyrel Prozac

TRADE NAME

Atarax Xanax Tranxene Ativan Buspar

IV. Sedative/Hypnotic Medications

GENERIC NAME

flurazepam temazepam
TRADE NAME

Dalmane Restoril 
amobarbital

chloral hydrate

V. Antimanic Medications

\section{lithium}

carbamazepine

cl.onazepam

valproic acid
Amytal

Noctec

Tegretol

Klonopin

Depakene, Depakote 